\title{
An overview of conventional and non-conventional techniques for machining of titanium alloys
}

Samuel Ranti Oke ${ }^{1,2}$, Gabriel Seun Ogunwande ${ }^{3}$, Moshood Onifade ${ }^{4}$, Emmanuel Aikulola ${ }^{3}$, Esther Dolapo Adewale ${ }^{3}$, Olumide Emmanuel Olawale ${ }^{3}$, Babapelumi Ebun Ayodele ${ }^{5}$, Fredrick Mwema ${ }^{6}$, Japheth Obiko ${ }^{7}$, and Michael Oluwatosin Bodunrin ${ }^{8,9, *}$

${ }^{1}$ Department for Management of Science and Technology Development, Ton Duc Thang University, Ho Chi Minh City, Vietnam

${ }^{2}$ Faculty of Civil Engineering, Ton Duc Thang University, Ho Chi Minh City, Vietnam

${ }^{3}$ Department of Metallurgical and Materials Engineering, Federal University of Technology Akure, PMB 704, Ondo State, Nigeria

${ }^{4}$ Department of Mining and Metallurgical Engineering, University of Namibia, P.O. Box 3624, Ongwediva, Namibia

${ }^{5}$ National Agency for Science and Engineering Infrastructure, PMB 391 Garki, Abuja, Nigeria

${ }^{6}$ Department of Mining, Materials and Petroleum Engineering, Dedan Kimathi University of Technology, Nyeri, Kenya

${ }^{7}$ Department of Mechanical Engineering, Jomo Kenyatta University, Nairobi, Kenya

${ }^{8}$ School of Chemical and Metallurgical Engineering, University of the Witwatersrand, Johannesburg 2050, South Africa

${ }^{9}$ African Academy of Sciences, Nairobi, Kenya

Received: 8 June 2020 / Accepted: 23 August 2020

\begin{abstract}
Machining is one of the major contributors to the high cost of titanium-based components. This is as a result of severe tool wear and high volume of waste generated from the workpiece. Research efforts seeking to reduce the cost of titanium alloys have explored the possibility of either eliminating machining as a processing step or optimising parameters for machining titanium alloys. Since the former is still at the infant stage, this article provides a review on the common machining techniques that were used for processing titanium-based components. These techniques are classified into two major categories based on the type of contact between the titanium workpiece and the tool. The two categories were dubbed conventional and non-conventional machining techniques. Most of the parameters that are associated with these techniques and their corresponding machinability indicators were presented. The common machinability indicators that are covered in this review include surface roughness, cutting forces, tool wear rate, chip formation and material removal rate. However, surface roughness, tool wear rate and metal removal rate were emphasised. The critical or optimum combination of parameters for achieving improved machinability was also highlighted. Some recommendations on future research directions are made.
\end{abstract}

Keywords: Titanium alloys / lubrication conditions / tool wear rate / finite element simulations / cutting forces / surface roughness / material removal rate

\section{Introduction}

Despite the attractive combination of properties that has seen titanium and its variants transcend predominantly from the aerospace and military applications in the 1950s to other niche applications - automotive, chemical, and biomedical - as we have today, the challenge of difficult machining is still persistent $[1,2]$. Hence, the long coveted widespread use of titanium-based alloys remains far from being realised. The attributes of titanium and its alloys

\footnotetext{
* e-mail: mobodunrin@gmail.com
}

which include low thermal conductivity, low elastic modulus, high chemical reactivity and high temperature strength qualify titanium-based alloys as difficult-tomachine material $[3,4]$. In fact, titanium and nickel-based alloys are considered the most difficult-to-machine structural materials used in engineering applications [5]. The poor thermal conductivity of titanium and its variants, the heat generated at the interface between the tool and workpiece and low volumetric heat capacity of titanium and its alloys retard dissipation of heat to the surrounding. So, about $80 \%$ of the heat generated at the interface is conducted by the tool, hence causing rapid tool wear [6-9]. The low elastic modulus of titanium alloys 
leads to high spring back which causes vibrations during machining and ultimately results in poor surface finish $[8,10]$. This poor surface finish is not desirable in machined titanium workpiece as they may contain stress raisers like cracks $[3,4]$ which would initiate fatigue failure under inservice conditions. The difficulty experienced during machining of titanium-based alloys varies with alloy chemistry, machining techniques, design and geometry of cutting tools and components, to mention a few.

A corollary to difficult machining of titanium-based alloys is high cost of manufacturing. Machining remains the most significant factor contributing to the high cost of titanium and its alloys [11]. The process accounts for $40 \%$ of the total cost of manufacturing titanium-based components [12]. Additionally, nearly $95 \%$ of bulk titanium material is machined away as swarf when manufacturing some aerospace grade components $[12,13]$. To fully take advantage of the high specific strength, excellent corrosion resistance and excellent biocompatibility of titaniumbased alloys when making highly efficient automotive engines and affordable biomedical implants for orthopedic treatments, the challenges posed by machining during processing of titanium-based components must be resolved.

Research efforts seeking to solve this problem have explored two major approaches. The first approach is a more recent one and it involves developing processing routes that minimize or exclude machining as one of the processing steps. Notable examples are conventional powder metallurgy or additive manufacturing processes [14-16] for producing near-net shaped components. The major disadvantage these techniques have is that large and complex shaped components are not be easily manufactured. Other examples of the first approach are advanced solid-state processes like FAST-forge $[11,17]$ and FASTDB processes [18]. These processes have been used to produce near-net shaped profiles with comparable properties to wrought alloys produced from conventional processing routes. In the FAST-forge process, titanium powder or swarf is consolidated using a combination of field assisted sintering technology (FAST) and a one-step precision hot forging, to produce a near-net shaped profile. FAST-DB is a process of developing functionally graded near-net shaped components by consolidating powders of dissimilar metals or alloys using FAST-forge process. The functionally graded components are produced as a result of diffusion bonding (DB) between the dissimilar powders [17]. Since these advanced techniques are still at the infant stage and still requires lots of research efforts to fully become a commercially viable process, the available literatures on this approach are limited and are not considered beyond this point in this review.

The second approach involves optimising machining parameters with the global objective of achieving the highest possible productivity and minimal waste generation [19-21]. Optimisation has become necessary because of the large number of parameters that influence the machinability of titanium alloys [4,22]. These parameters are interdependent and their influence on machinability varies with different machining techniques. The different parameters influencing machining are presented in the subsequent sections of this review. Waste reduction during machining is imperative because it is a major criterion that must be met to achieve sustainable manufacturing. To this end, machinability indicators such as cutting forces and tool wear rate must be lowered, tool life must be enhanced, chip formation must be easily controlled, surface finish of workpiece must improve, and metal removal rate must be maximized.

With the availability of numerous machining techniques, it is impossible to capture all the parameters affecting machinability in a single study. Hence, researchers have studied different sets of machining parameters with the aim of achieving the aforementioned objectives. This resulted in a huge number of publications on machining of titanium alloys such that each machining technique has a wide range of articles which considered the effects of different combination of machining parameters on some machinability indicators. To date, it is extremely challenging to write a comprehensive review article on the machining of titanium alloys [4]. However, the large number of research articles on titanium alloys has called for a good number of high-quality reviews which focused on the different aspects of machining. For example, Ezugwu and Wang [6] reviewed the machinability of titanium alloys and provided detailed information on the effect of cutting parameters on some machinability indicators. They established that tungsten carbide tools offered the best performance during machining of titanium alloys. Raman et al. [23] carried out a critical review on the performance of cutting tools during high speed milling and turning of titanium alloys. They indicated that binderless cubic boron nitride (BCBN) tools are best suited for high speed machining. Veiga et al. [4] in their review on machinability of titanium alloys focused on turning process and gave a detailed account on the influence of titanium properties on several machinability indicators. Niknam et al. [3] in their review on machinability and machining of titanium alloys focused on milling process and established that high surface temperature was the main reason for poor surface roughness. They covered extensively the different factors affecting chip formation during machining of titanium alloys. These above stated examples focused on one or more aspects of machining techniques that involve direct contact between cutting tool and the workpiece. In other reviews, Gupta et al. [24] among other researchers [25] have focused on machining techniques that do not require contact between the tool and the workpiece.

In this paper, we have identified different machining techniques and group them into conventional and nonconventional techniques based on the contact between the tool and the workpiece. Each category of machining techniques has several review articles which has helped readers to keep up with the recent advances in titanium machining, but to the best of the authors' knowledge, a single review article which covers both conventional and non-conventional machining techniques is rarely available. Hence, we attempt to provide a succinct review which captures the prominent machining techniques for titanium processing. The authors believe that this review will be of great benefit to researchers who are just developing new interest in titanium machining as it gives a succinct 


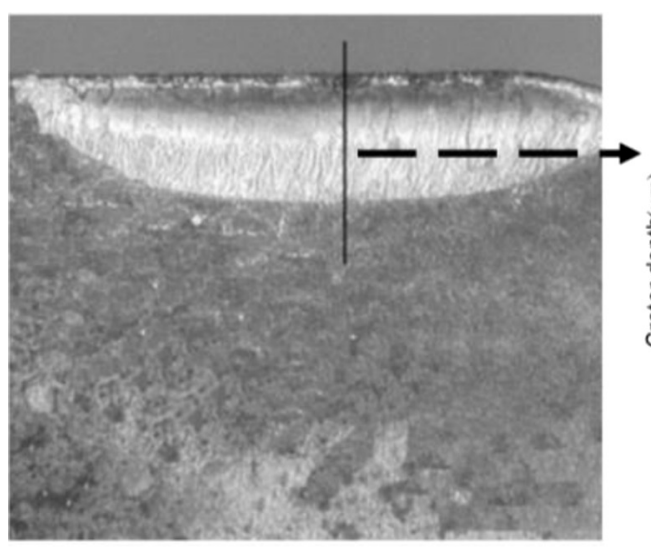

(a)

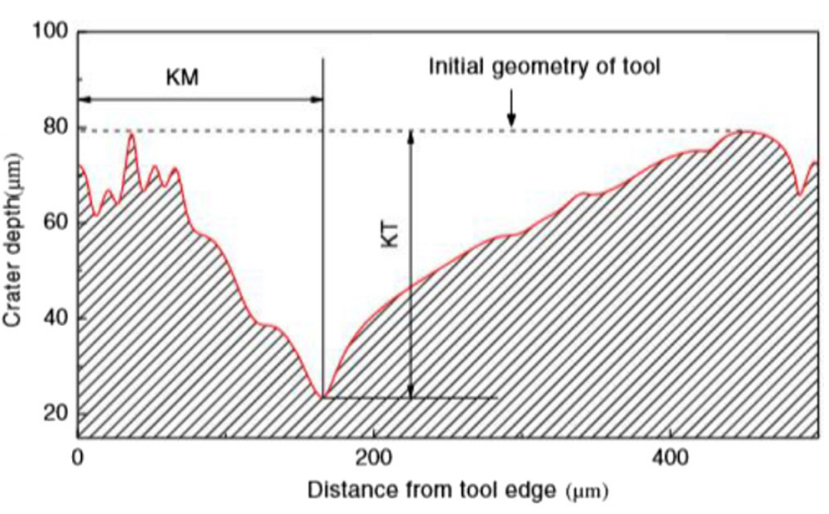

(b)

Fig. 1. Tool crater section measurement of ISO K30 WC (a) wear of rake face and (b) crater geometry with cutting speed $=90 \mathrm{~m} / \mathrm{min}$, feed $=0.1 \mathrm{~mm} / \mathrm{rev}$, cutting time $=5 \mathrm{~min}$, reuse with permission from Springer Nature, Yang et al. [46].

account of the different machining techniques, the important machining parameters and key machinability indicators. The experienced and new researchers can easily refer to the wide range of other research and review articles that are captured in this paper for further reading. This paper did not cover the description of machining operations as there are numerous comprehensive reviews [8,25-29] on a specific type of machining technique for titanium alloys.

\section{Machining techniques}

There is an increase in the demand for titanium alloys especially in the aerospace industries [30,31]. In aerospace industries, titanium alloys are not only used for making fan blades, landing gear and other engine parts, but also for making fasteners for new lightweight carbon fiber fuselage and wings [32]. An example is the transition to carbon fiber fuselage and wings in Airbus A380-800, a major change from the materials selected for Airbus A340 [32,33]. The choice of using titanium alloys particularly for carbon fibre fuselage fasteners is informed by its superior compatibility with carbon in comparison to aluminum alloys [33]. Also, increase in bone fractures in the ageing population has increased the demand for affordable titanium-based implants and medical devices for orthopedic and dental treatments [34-36]. Consequently, a wide range of machining techniques are now being explored to increase production of titanium parts [37]. These techniques are discussed under the broad topics of conventional machining and non-conventional machining.

\section{Conventional machining}

The major signature of conventional machining is that there is direct contact between the cutting tool and the workpiece. As shown in Supplementary Table S1, the different machining operations under this category include turning, milling and drilling which are performed under dry or wet conditions [38-40]. These operations have other variants such as micro milling, face milling, planar milling, angular milling, horizontal drilling, directional drilling, ultra-precision machining to mention a few [41-43]. Table S1 suggests that Ti-6Al-4V was mostly investigated and the different cutting parameters that were considered are equally listed. The parameters for these operations are similar but machining conditions are not the same. Researchers had often investigated the influence of parameters such as depth of cut, spindle speed, spindle power, cutting material, cutting speed, feed rate on machinability indicators such as the tool wear rate, chip formation and surface roughness of the workpiece. The disparities in machining conditions make it difficult to compare results. In conventional machining, one of the common practices to date is to cut titanium at lower cutting speed but with high depth of cut [33,44]. This makes it impossible to achieve typical rapid production rate that is obtainable in steel machining. Damage to workpiece and cutting tools has been reported as the major challenge faced when machining titanium-based alloys using any of the conventional machining operations [45]. Figures 1 and 2 show cutting tool damage characterized by flank wear, crater wear and rake face wear [46,47].

To minimize tool wear rate, improve surface integrity of workpiece, understand dominant mechanisms for tool wear and establish optimal parameters for specific machining operation, different conditioning of the workpiece or tool were performed. The conditioning approach involved using lubrication [48-50], laser or plasma heating, cryogenic cooling [49], intermittent cutting [51] or combination of two or more of these conditions [52-54]. Additionally, the in-service performance of existing and newly modified cutting tools was evaluated $[9,55-58]$.

\subsection{Conditioning of workpiece or tool}

This section provides an overview of the different conditioning methods that have been used to reduce tool wear and surface roughness of workpiece during conventional machining of titanium and its variants. To fully 

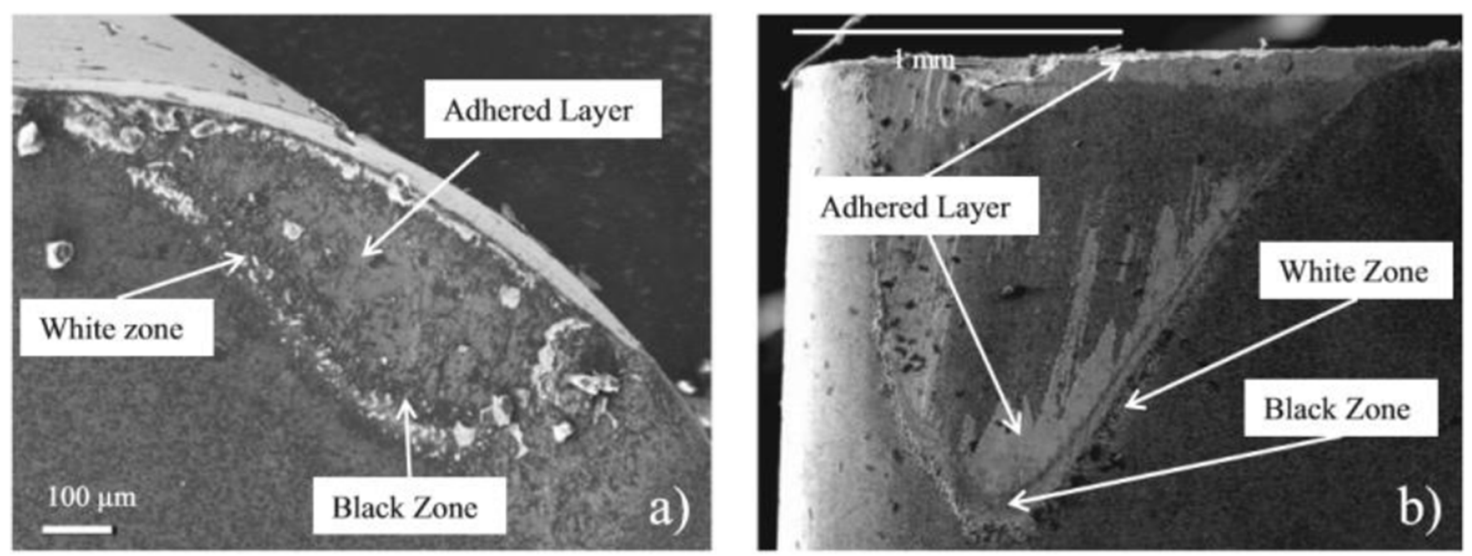

Fig. 2. SEM image of the worn surface of (a) cBN rake face and (b) cBN flank face under through coolant turning with cutting speed $=250 \mathrm{~m} / \mathrm{min}$, feed $=0.1 \mathrm{~mm} / \mathrm{rev}$, and depth of cut $=0.15 \mathrm{~mm}$ and cutting time $=55 \mathrm{~s}$, reuse with permission from Springer Nature, Aramesh et al. [47].

appreciate the importance of these conditioning methods, the effects of dry machining on cutting forces, tool life and surface finish are first described. Tool wear rate and surface roughness are machining responses that are used to measure tool life and surface finish of the workpiece. The various conditioning methods covered in this section are discussed based on tool wear rate and surface roughness.

\subsubsection{Dry machining}

As mentioned earlier, machining titanium and its alloys comes with generation of heat at machining zone, high spring back, diffusion of elements between the tools and workpiece. All these affect the surface finish of the workpiece and the tool life [3,6]. In dry machining, due to lack of externally aided cooling, heat is generated at the tool-chip interface of the machining zone and does not dissipate easily to the surroundings. Hence, heat is conducted by the tool and causes rapid tool wear. For example, tungsten carbide tool that is supposed to be one of the best cutting tools for titanium machining has a tool life of $<5$ min when used under dry machining conditions and this is even less at higher cutting speed [8,59]. The use of coated tools was explored as an alternative to increase tool life in dry machining, it was found that tool life could be extended to about $10 \mathrm{~min}$ based on optimised cutting parameters, but the challenge of built up edges which increase surface roughness remained [8]. Generally, the surface finish of workpiece during dry machining is poor, at low cutting speed, titanium undergoes strain hardening which promotes the formation of built up edges. These built up edges are precursors to poor surface finish of titanium workpiece.

While high temperature generated during dry machining may be beneficial in terms of lowering cutting forces, it does not necessarily translate to improved tool life or surface finish. Therefore, high rate of tool wear and poor surface finish induced by thermal and residual stresses make dry machining unattractive for shaping titanium and its alloy [48]. To improve surface roughness and tool life, different external assisted conditions were developed to improve machining response. Of these conditions, lubrication techniques using different cutting fluids are first discussed in Section 3.1.2.

\subsubsection{Lubrication}

Lubrication techniques can be classified into continuous flooding lubrication or minimum quantity lubrication depending on the volume and flow rate of cutting fluid that is applied during machining. Typical cutting fluids include water-based emulsion which contains complex petrochemical compounds and vegetable oil-based fluids such as canola oil, palm oil, castor oil, sesame oil and sunflower oil [8]. The formulation of the different cutting fluids, and advantages and disadvantages have been highlighted by Osman et al. [60]. Flooding of the machining zone with cutting fluids of about $100 \mathrm{~L} / \mathrm{h}$ is a common practice in conventional machining as it provides cooling effect and lubrication [61]. Depending on the choice of cutting fluid, the heat generated at the cutting area is effectively cooled using water as cutting fluid for example, the continuous flooding helps in effectively removing chips which also conduct away the heat generated [10]. Should the fluid contain lubricant like soluble or straight oil as water cannot lubricate effectively, it reduces the coefficient of friction at the tool-chip interface $[8,10]$. Consequently, this improves surface finish of workpiece and the tool life. Namb and Paulo [62] investigated machinability of Ti-6Al$4 \mathrm{~V}$ at varied cutting speed of $45,90,135 \mathrm{~m} / \mathrm{min}$, depth of cut of 0.5 and $0.75 \mathrm{~mm}$ and feed rate of $0.1,0.2$ and $0.3 \mathrm{~mm} /$ rev. They found that tool life increased by $30 \%$ in comparison with dry machining when cutting fluid containing $75 \%$ water was applied. Cutting at higher cutting speed of about $135 \mathrm{~m} / \mathrm{min}$ and feed rate of $0.3 \mathrm{~mm} /$ rev was possible and excellent surface finish was obtained on the machined Ti-6Al-4V.

It has been reported that increasing the pressure of cutting fluids during wet machining improves tool life and surface finish of titanium alloys [49]. High pressure water jet assisted machining (HPWJAM) has also been performed on Ti555-3 alloy, it was reported that chips 
were broken by the water at optimal pressure of 200 bar and this resulted in lowering the temperature at the tool tip and improving tool life from eight minutes in dry machining to twenty-two minutes in HPWJAM. At a lower pressure of 100bar, cutting forces was reduced by $23 \%$ [63]. In another study, Ayed and Geriman [64] reported that the tool life increased by a factor of 8 during HPWJAM of Ti555-3. The cutting speed of up to $75 \mathrm{~mm} / \mathrm{min}$ gave good machinability but above this speed, the HPWJM was ineffective. The tool notch wear was significantly affected by feed rate due to high strain rate sensitivity of the alloy. The wear mechanism changed from plastic deformation, adhesion and abrasion to solely adhesion when lubrication changed from conventional to HPWJAM. Similar observation of reduction in cutting forces and residual stresses have been reported by other authors on high pressure water jet assisted machining of Ti6Al-4V alloy [65-67].

The major drawback of continuous flooding machining is that it does not meet the requirements for sustainable manufacturing. There are concerns on environmental safety due to disposal of used cutting fluids. Also, high energy consumption associated with pumping of the cutting fluids is another challenge. Therefore, researchers have considered alternative lubrication techniques such as minimum quantity lubrication (MQL) [49] or minimum quantity cooling lubrication (MQCL) [68] and atomization-based cutting fluids (ACF) [69] where only about 50 $100 \mathrm{~mL} / \mathrm{h}$ of cutting fluid are required to achieve improved tool life and surface integrity of the titanium workpiece. A comprehensive review of these techniques was done recently by Revuru, et al. [8] on Ti-6Al-4V and Pervaiz et al. [50] on Ti6Al-4V and other biomedical grade alloys Ti 6 Al7Nb, Ti13Nb13Zr and Ti12Mo6Zr. The summary of the review articles indicated that MQCL offer the best machinability in comparison with other techniques such as dry machining and continuous flooding machining. Cutting forces and tool wear were lowered due to lubrication effect of the oil mist while compressed air offered cooling which alleviated thermal stresses during machining [49,70]. MQCL offered good machinability in Ti-6Al-4V even at high feed rate $(0.3 \mathrm{~mm} / \mathrm{rev})$ and cutting speed $(150 \mathrm{~mm} / \mathrm{min})$ when flow rate was $100 \mathrm{ml} / \mathrm{hr}$ [71]. This was possible because the compressed air and oil penetrated into the tool-workpiece interface. Like the traditional flooding technique, the MQCL technique was improved through the introduction of nano particles like $\mathrm{Cu}, \mathrm{MoS}_{2}$, $\mathrm{Al}_{2} \mathrm{O}_{3}$ and graphite [70] that act as solid lubricants or through combination with other process like cryogenic cooling [70]. However, the authors reported that this approach was not cost effective and may not be sustainable. Overall, there is need for more studies involving optimisation of MQCL technique because studies from several authors show that machining outcomes are significantly dependent on cutting parameters, flow rate of the fluid as well as alloy chemistry $[10,60,72,73]$.

Apart from the lubrication techniques discussed in this section. The other externally assisted machining techniques include thermal assisted machining [74], cryogenic treatment [54] and electro-pulse treatment. [43,75]. These techniques are discussed in Sections 3.1.3 to 3.1.5.

\subsubsection{Laser assisted machining}

Titanium alloys such as $\alpha+\beta$ Ti-6Al-4V and near beta Ti553 exhibit high temperature strength but the near alpha alloys such as BTi-6431S have even higher high temperature strength in comparison with the $\alpha+\beta$ and near beta alloys such that they could maintain their strength up to $600^{\circ} \mathrm{C}$. Consequently, thermal assistant in form of pretreatment using induction heating is applied to the workpiece to soften the material before machining. It was reported that cutting forces reduced significantly using this approach, but high thermal load on the tool led to rapid tool wear [52]. The use of laser or plasma as heat source in thermal assistant machining offers localized heating at the region to be machined such that only the volume of metal to be removed is targeted. Laser heat source is preferred to plasma due to higher heating density, controllable spot size and heat affected depth [42]. The effect of laser assisted machining on cutting forces, tool life and surface integrity of machined parts was previously investigated. Findings have shown that cutting forces reduced under laser assisted machining condition regardless of alloy compositions. The heat from the laser softens the work material and consequently reduces the energy required for cutting. In contrast, findings on the effect of laser assisted machining on tool life and surface finish have been inconsistent. Sun et al. [76] and Dandenker et al. [77] have reported significant improvement in tool life with laser assisted machining of Ti-6Al-4V alloy, while Bermingham et al. [78,79] reported that temperature increase from thermal assistance of the laser enhanced diffusion induced tool wear, hence reducing the tool life during machining of Ti-6Al-4V. This was corroborated by the finding of Gao et al. [80] during laser assisted machining of near alpha alloy. It was reported that laser assisted machining cannot significantly improve tool life during machining of BTi-6431 S. On the surface roughness of machined titanium parts, LAM effect has remained inconclusive as divergent results were obtained. Additionally, studies on LAM have focused more on evaluating cutting forces, tool life and chip formation. The effect of LAM on chip formation of titanium alloys is highly dependent on machining parameters and alloy composition. Sun et al. [81] evaluated the effect of laser beam on chip formation during laser assisted machining of Ti-6Al-4V. They found that two types of segmented chips and additional continuous chip were formed. The nature of the chips formed and transition of the chip from one form to the other were strongly influenced by cutting speeds and laser power. At low and high cutting speeds different types of segmented chips were observed while the continuous chip that was formed in between the segmented chips was strongly influenced by laser power.

Braham-Brouchnak et al. [52] conducted a study on the laser assisted machining of Ti553-3 alloy, a more difficultto-machine alloy than $\mathrm{Ti}-6 \mathrm{Al}-4 \mathrm{~V}$. The researchers adopted optimised parameters recommended by Germain et al. [82] for laser positioning during machining of Ti-6Al-4V. For the Ti-5533 alloy, the authors found that laser assistance reduced cutting forces significantly especially when surface temperature is high, but surface roughness 


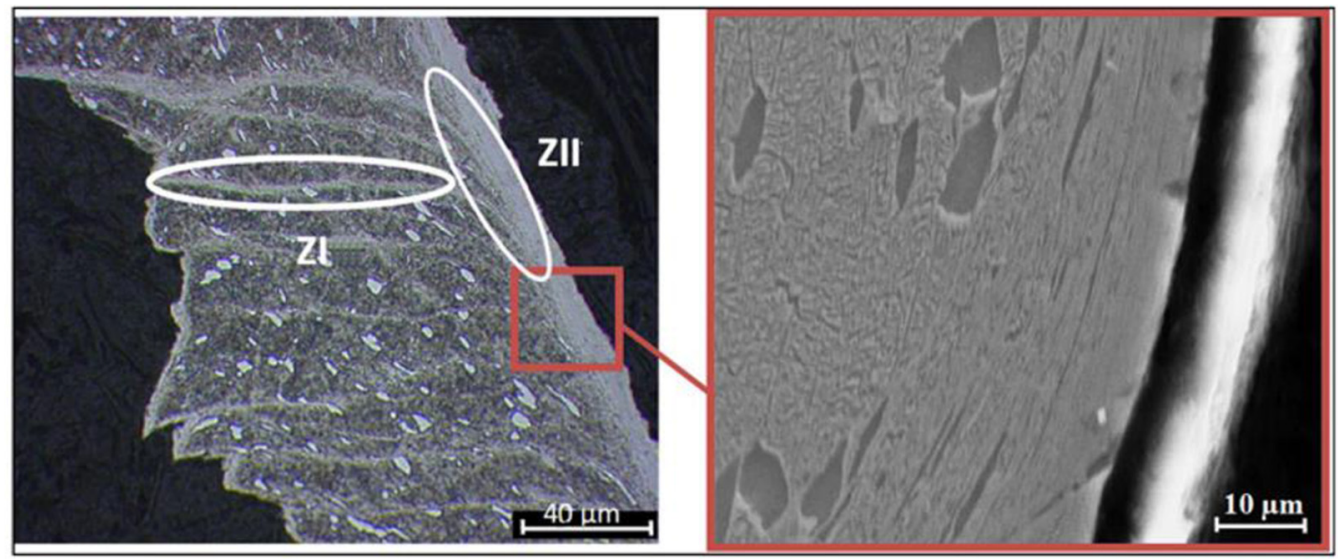

Fig. 3. Observation of white bands in the shear zones of chip formed during laser assisted machining of Ti555-3 alloy, cutting speed $=$ $90 \mathrm{~m} / \mathrm{min}$ and feed $=0.15 \mathrm{~mm} / \mathrm{rev}$, cutting tool $=$ CP 500, reuse with permission from Springer Nature, Bouchnak et al. [52].

was not affected. The surface temperature was greatly influenced by cutting parameters and it increased with decreasing depth of cut, cutting speed and feed rate. The alloy exhibited white bands within the shear zones of the chip (Fig. 3) as evidence of severe plastic deformation or adiabatic heating during machining. This differ from the observation of Germain et al. [82] on laser assisted machining of Ti-6Al-4V where such white bands were not seen.

In another study on Ti-6Al-4V and BTi-6431S nearalpha titanium alloy, it was also found that varying laser power has significant effect on the cutting forces and this effect is alloy dependent. Average reduction of cutting force was $31.96 \%$ in Ti-6Al-4V when laser power was observed with laser power of $1382 \mathrm{~W}$ while $16.95 \%$ reduction was reported for the same laser power in BTi-6431S near-alpha titanium alloy. Additionally, tool wear mechanism changed from flank wear in conventional machining to diffusion mechanism in laser assisted machining of both alloys [80].

\subsubsection{Cryogenic cooling}

Cryogenic conditioning involves the use of liquid nitrogen with temperature of $-196{ }^{\circ} \mathrm{C}$ to either treat the cutting tool or cool the cutting zone during machining [83]. The advantage of this approach is that it is environmentally friendly because the use of lubricants that are not environmentally friendly is eliminated. Some researchers reported that tool wear rate was reduced since workpiece was less sticky and coefficient of friction was minimized when cryogenic cooling was applied [8,53]. Additionally, feed force and cutting force were significantly reduced up to $50 \%$ under optimised conditions during machining of Ti-6Al-4V [84,85]. In a recent study by Park et al. [49], it was shown that cryogenic treatment was only beneficial at the initial stage of milling as tool wear rate and cutting forces reduced. However, with increasing milling time, Ti-6Al-4V hardens as a result of the continuous cooling by liquid nitrogen. Therefore, cutting forces and tool wear rate increased with prolonged milling time. It was recom- mended that cryogenic treatment should only be applied on the tool to prevent tool wear and to reduce cutting force.

On the surface roughness of machined workpiece, researchers have shown that cryogenic treatment of tool offer superior surface finish over dry machining and continuous flooding machining $[53,86]$. It is important to point out that researchers focused more on understanding the effect of cryogenic cooling on tool wear rate, chip formation and cutting force rather than surface finish of the workpiece.

\subsubsection{Electro-pulse treatment and intermittent cutting}

Single point diamond turning (SPDT) also known as ultraprecision machining (UPM) [51] is becoming an attractive machining operation for titanium alloys. However, due to poor surface integrity and high rate of tool wear caused by the chemical and mechanical interaction of titanium alloys and the tools, the process has suffered some setbacks. Research efforts are underway to improve SPDT via electro-pulse treatment (EPT) and intermittent cutting. $\mathrm{Wu}$ and To [75] showed that the EPT improved the plasticity of $\mathrm{Ti}-6 \mathrm{Al}-4 \mathrm{~V}$ by refining the grains as EPT frequency increased. This led to improved machining in terms of lower surface roughness in the nanometer range and cutting forces (Fig. 4) when compared to SPDT without electro-pulse treatment. The improvement in surface roughness is also shown in the surface topography image presented in Figure 5. Shallow valleys and short ridges are evident after EPT.

Apart from the electro-pulse treatment, Yip and To $[43,87]$ in different studies showed that using magnetic field generated eddy current damping effect or intermittent cutting enhanced surface finish of Ti-6Al-4V and the material removal rate. The intermittent cutting was achieved by pre-cutting microgrooves on the Ti-6Al-4V alloy prior to SPDT. These microgrooves served as physical spaces which allow for escape of heat from the diamond cutting zone during SPDT and consequently improved machinability of the alloy. 

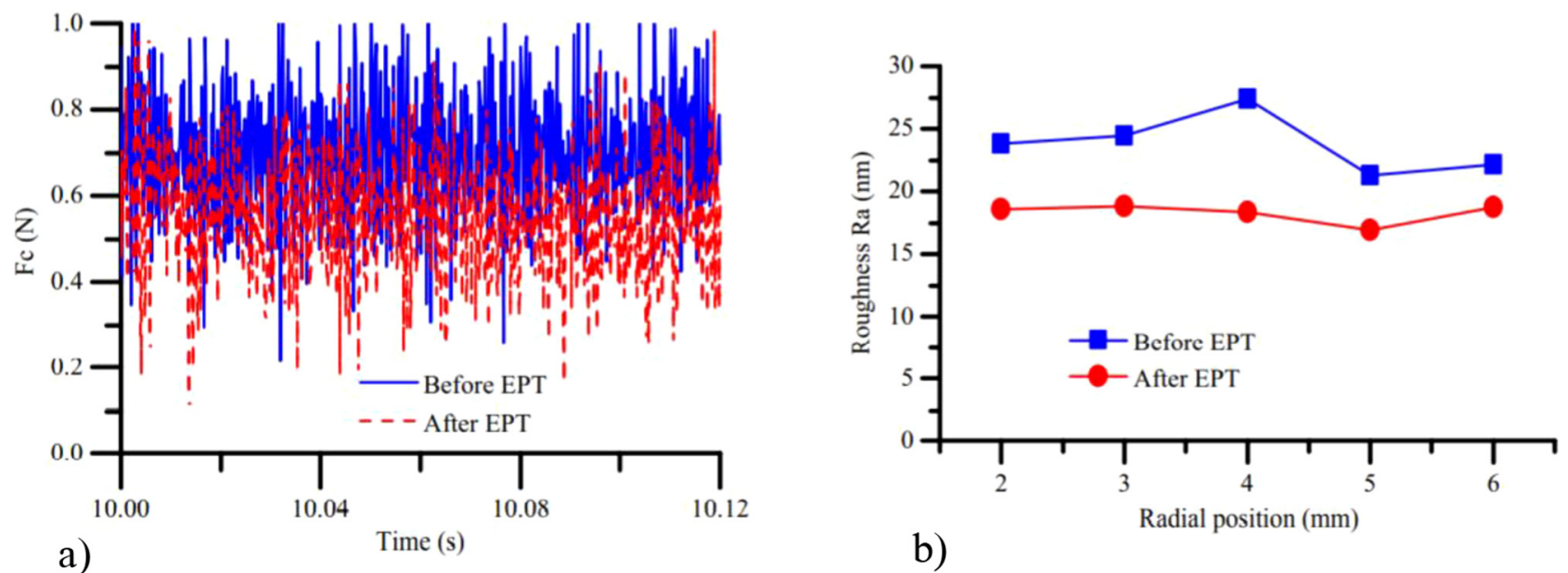

Fig. 4. Reduction in (a) cutting forces and (b) surface roughness due to Electro Pulse Treatment during ultra-precision machining of Ti-6Al-4V, reused with permission from Springer Nature, Lou et al. [51].

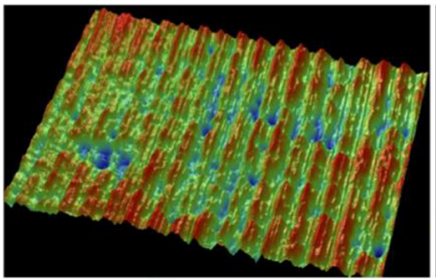

(a) Before EPT

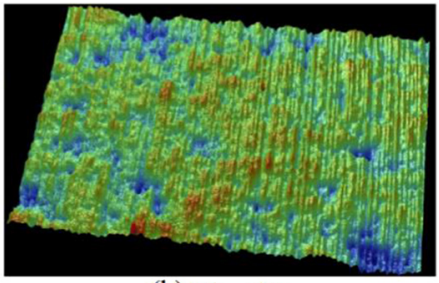

(b) After EPT

Fig. 5. Surface topographies of ultra-precision machined Ti-6Al$4 \mathrm{~V}$ sample, (a) before EPT and (b) with EPT, reuse with permission from Springer Nature, Lou et al. [51].

\subsubsection{Exploration of cutting tools}

The different tool types and grades that are used in conventional machining operations are listed in Table S1 [117,119-121,124-132]. Although different tool wear mechanisms such as plastic deformation, adhesion and abrasion were mentioned in the preceding paragraphs, crater wear has been reported as the main mechanisms affecting the life span of cutting tools especially at cutting speed of $61-$ $122 \mathrm{~m} / \mathrm{min}[33,88]$. Crater wear is considered as the precursor for flank wear since crater wear must cause edge damage before plastic deformation progresses to the tool flank $[32,33]$. Hatt et al. [32,33] have recently investigated the mechanism of crater wear in detail. They established that diffusion bond occurred between the workpiece and the tool, resulting into the formation of $(\mathrm{Ti}, \mathrm{V}) \mathrm{C}$ layer. This diffusion bond was caused by chemical reaction at the interface of the workpiece and WC tool. It was reported that all titanium alloys form diffusion bond with the tool except Ti-6246 and this can be described in terms of the relationship between the thickness of the $\mathrm{TiC}$ layer formed and molybdenum equivalent. As shown in Figure 6, TiC has higher thickness in commercially pure titanium, but the thickness of the layer depleted with increasing molybdenum equivalent in $\alpha+\beta$ and $\beta$ alloys. SEM images corroborating this hypothesis are presented in Figure 7 . They concluded that $\mathrm{TiC}$ reduced the propensity

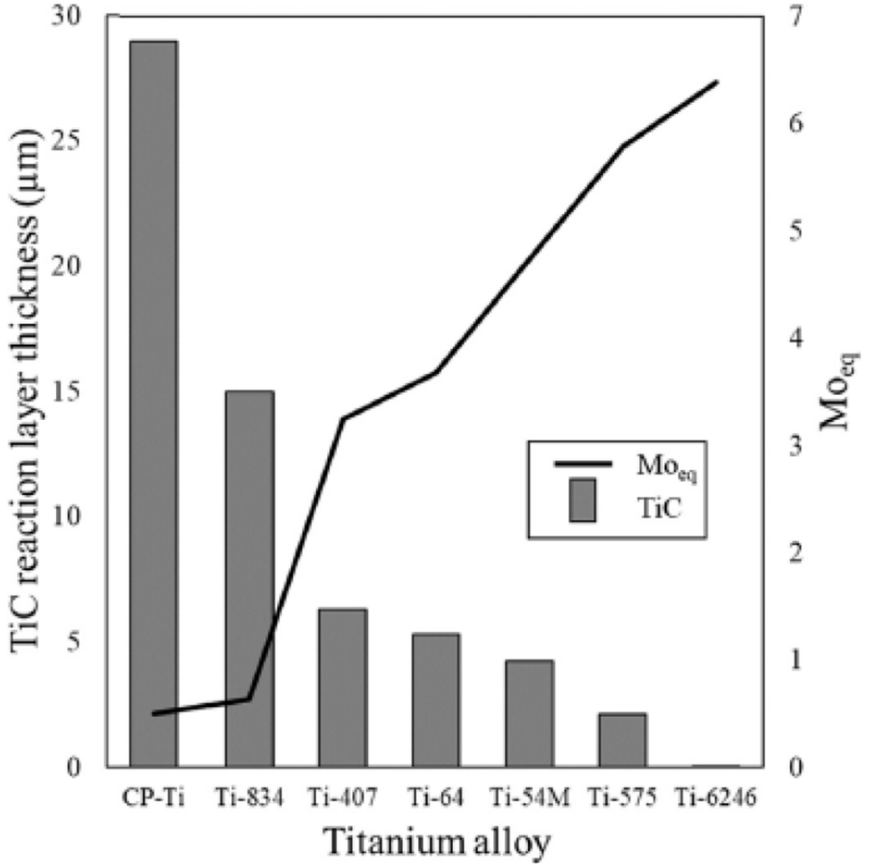

Fig. 6. Thickness of $\mathrm{TiC}$ layer as a function of molybdenum equivalent, reuse with permission from Elsevier, Hatt et al. [33].

of cutting tool to crater wear and as such commercially pure titanium and other alpha alloys have better machinability in comparison with other types of titanium alloys.

As shown in Table S1, Tungsten carbide based tools are mostly used in conventional machining [53,86], but researchers have explored different alternatives to minimize or prevent tool wear through coating, imprinting microgrooves, electrical insulation [39] or comparing different tools with newly designed ones. Maity and Pradhan [89] reported that improved machinability was obtained when microgrooves were imprinted on the rake 


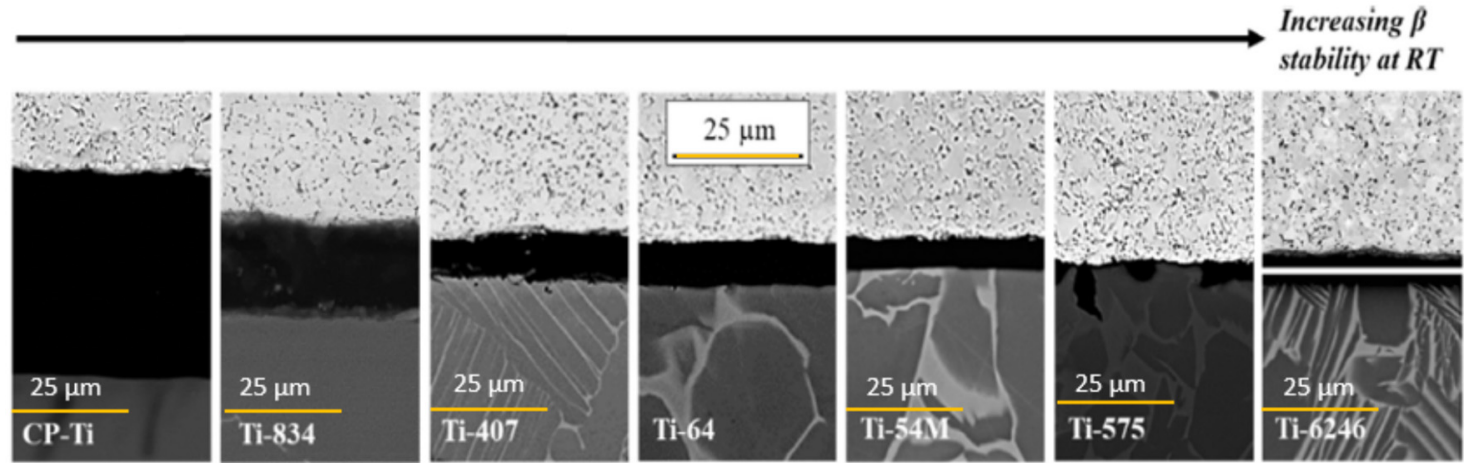

Fig. 7. SEM-BSE images of the TiC reaction layer interface between the Wc-6\%Co tool insert and CP-Ti; Ti-834; Ti-407; Ti-64; Ti-54M; Ti575; and Ti-6246 reuse with permission from Elsevier, Hatt et al. [33].

surface of the tool prior to machining. Ren et al. [9] compared PCD and PCBN tools during dry turning of titanium. It was reported that polycrystalline diamond (PCD) tool had better wear resistance to polycrystalline cubic boron nitride (PCBN) tool. It also offered superior surface finish at high cutting speed. Pervaiz et al. [59] showed that TiAlN coated inserts using physical vapour deposition (PVD) performed better at high cutting speed $(90 \mathrm{~mm} / \mathrm{min})$ than the uncoated inserts, but uncoated cutting inserts should be used at lower cutting speed as they offered better machinability in that condition. An et al. [55] compared ( $\mathrm{Ti}, \mathrm{Al}) \mathrm{N}+\mathrm{TiN}$ and $\mathrm{Ti}(\mathrm{C}, \mathrm{N})$ $+\mathrm{Al}_{2} \mathrm{O}_{3}+\mathrm{TiN}$ coated and uncoated tools during face milling of Ti-6242S and Ti-555 alloys. The (Ti,Al)N + TiN tool was coated using physical vapour deposition while $(\mathrm{Ti}, \mathrm{Al}) \mathrm{N}+\mathrm{TiN}$ was coated using chemical vapour deposition. They found that $(\mathrm{Ti}, \mathrm{Al}) \mathrm{N}+\mathrm{TiN}$ coated tool had superior wear resistance and exhibited longer tool life under all face milling conditions. In general, the uncoated exhibited inferior machining performance in comparison with the coated. The uncoated tool suffered severely from adhesive and abrasive wear.

\subsubsection{Summary of conventional machining processes}

The studies above clearly indicate that researchers have considered different approaches [90-100] to improve life span of cutting tools and machinability of titanium alloys in general. However, due to the large number of variables involved, improved machinability is restricted to the specific machining operation and type of alloy investigated. In fact, in most cases, only a few of the factors that influence machining are accommodated in experiments in order to avoid large experimental matrix and associated cost. Consequently, mathematical modelling, numerical simulation, Taguchi experimental design, full factorial experimental design and finite element modelling are now being utilised in studying the influence of machining parameters on the tool life and machinability of titanium alloys $[20,38,67,90-92]$. These paved way for incorporating a large number of machining variables for modelling and simulations and the outcomes are validated experimentally. The benefit of adopting these research methods is that cost of experiment can be reduced significantly and the best combination of parameters for a specific machining operation can be obtained. Despite these efforts, the dependency of machining outcomes on alloy chemistry and the huge amount of material machined away as swarf during conventional machining techniques make it imperative to explore non-conventional machining operations. Additionally, the improvements in machinability using these conventional techniques have not necessarily translated to higher production rate in manufacturing of titanium-based components.

\subsection{Non-conventional machining}

Over the years there have been campaigns to develop new methods that would resolve the difficulties associated with cutting tools during machining of titanium alloys and other hard-to-cut metals. Therefore, machining operations which do not require any form of contact between the tool and the workpiece began to gain attention. Some of the common machining techniques covered in this review include electrochemical machining (ECM) [101], laser beam machining (LBM) [81,102], electrical discharge machining (EDM) [103], chemical machining [104] and magnetic abrasive finishing, a surface finishing technique $[105,106]$. Among these techniques, the chemical machining process has not received so much attention in recent time. The process involves masking the area of the titanium workpiece that is not to be machined with a chemically resistant material while the area to be machined is dissolved in a strong chemical reagent [104]. The other non-conventional machining techniques started as far back as early 1940s when titanium alloys began to emerge as a potential commercial material. To date, ECM, LBM and EDM are still very much in use and still receiving considerable amount of attention from researchers. The same principle of non-contact between the tool and the workpiece hold for ECM, LBM and EDM. The problems of high rate of tool wear and residual stresses on workpiece that are associated with conventional machining are controlled to a higher degree. However, incidence of heat affected zone and recast layers have been reported in electric discharge machining $[107,108]$ as well as laser beam machining [109]. This is because materials removal in LBM and EDM processes is achieved by melting and evaporation. Figure 8 shows the recast layers formed on the surface of $\mathrm{Ti}-3 \mathrm{Al}-2.5 \mathrm{~V}$ subjected to powder mixed dielectric 

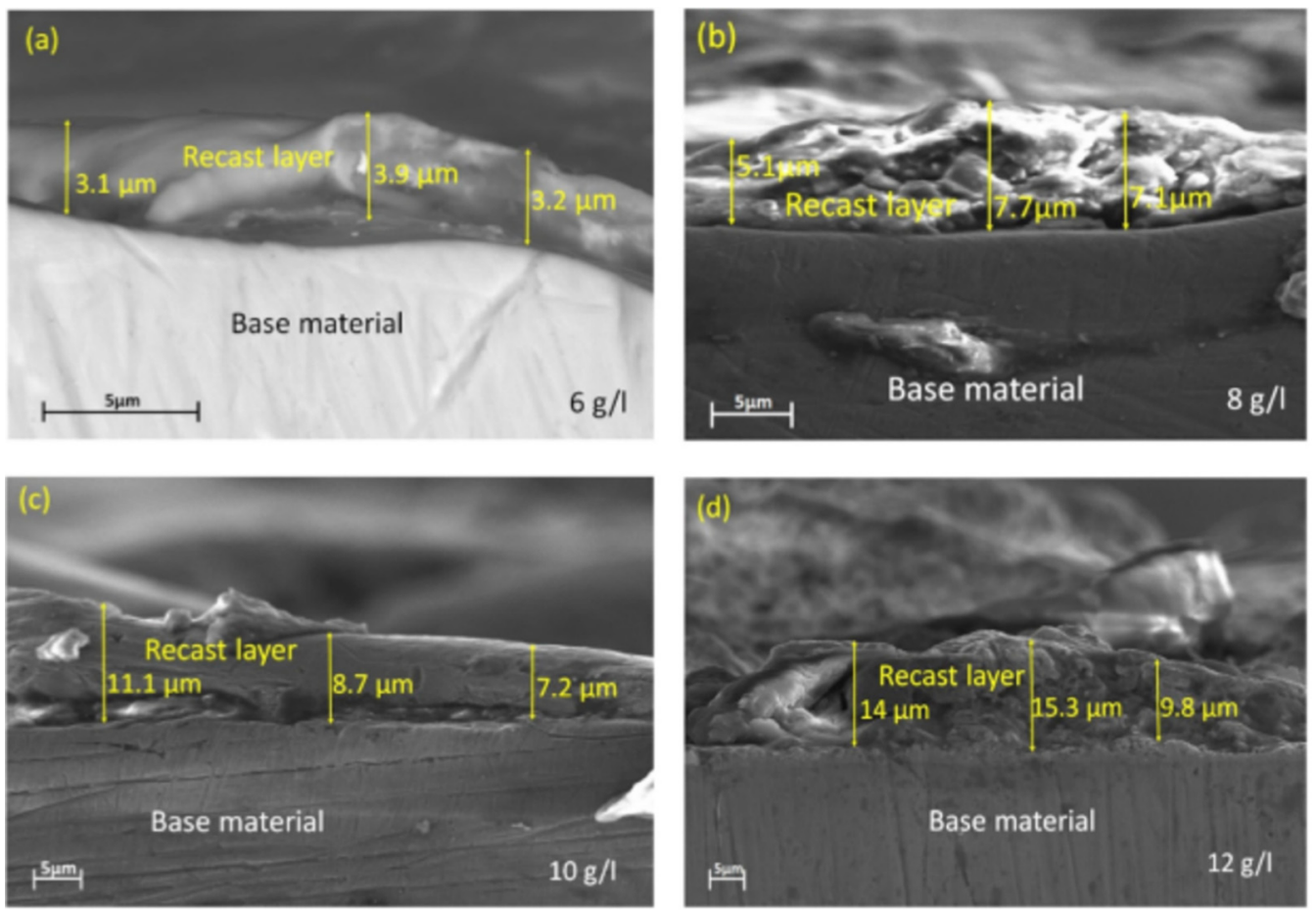

Fig. 8. Recast layers shown in scanning electron images of Ti-6Al-4V subjected to mixed powder dielectric during micro-EDM at different concentrations (a) $6 \mathrm{~g} / \mathrm{l}$, (b) $8 \mathrm{~g} / \mathrm{l}$, (c)10 g/ 1 and (d) $12 \mathrm{~g} / \mathrm{l}$, reuse with permission from Elsevier, Sharma et al. [108].

micro-EDM [108]. The major advantage of non- conventional machining processes is that machining of any hardto-cut metal to high accuracy is possible regardless of the complexity of the shape. These processes can also be used for machining at both large and micro scales, but machining at micro scale may require additional accessory like in the case of wire or vibration assisted ECM $[110,111]$ and jet-ECM [112]. Another non-conventional machining process that differs from the LBM, EDM and ECM is ultrasonic machining (USM) [113]. The process was patented in the 1950s and was originally developed to drill holes in brittle materials such as ceramics with hardness higher than HRC $40[27,29,42,114]$. However, it has been applied successfully on titanium alloys and other tough materials $[29,114]$. This technique differs from other non-conventional techniques in that there is an indirect contact between the workpiece and the tool, leading to reduced tool life, but the ultrasonic vibration limits tool wear in comparison with the conventional machining process. Additionally, the problem of recast layer and heat affected zone experienced in EDM and LBM are eliminated.

The detailed descriptions of all the principles of operation of the various non-conventional machining techniques are well documented $[25,27,28]$ and as such, not within the purview of this paper. Table S2 shows a summary of some of the research work that was carried out on the non-conventional machining of titanium and its alloys. Similar to the conventional machining in Table S1, Ti-6Al-4V is the most investigated alloy. In these studies, the researchers measured machinability with two primary indicators which include the material removal rate (MRR) and surface roughness (Ra). The independent parameters that affect the MRR and Ra when these non-conventional techniques are used are presented in Table 1. Researchers vary these parameters and report on the optimum combination of parameters for efficient machining of titanium alloys.

\subsubsection{Electrical discharge machining}

Recently, researchers have conducted more studies on the EDM process than other non-conventional techniques. Hence, the higher number of articles published on a wide range of studies involving the EDM processes. Two critical review articles on the principles of EDM and their parametric effects on machinability of titanium alloys were published recently $[25,28]$. The authors highlighted the different parameters affecting MRR, tool wear and surface roughness in EDM machining. Additionally, they noted that outstanding progress has been made using a mixed machining method like ultrasonic assisted EDM over other EDM processes including wire-EDM, sinking EDM, powder EDM and micro EDM. When carrying out EDM at micro scale, electrode wear was considered as the major concern because it determines sparking conditions for metal removal. They indicated that copper electrode has low wear rate in comparison with graphite, brass and zinc but, it offered less MRR in micro- EDM and EDM at larger scales. Tubular electrode was reported to have superior resistance to tool wear when compared with cylindrical tool. Therefore, tool material and geometry are important factors to consider when selecting micro-EDM tool. They mentioned that recast layer which is one of 
Table 1. Typical parameters considered during non-conventional machining.

\begin{tabular}{|c|c|c|c|c|}
\hline Parameters & \multicolumn{4}{|c|}{ Machining techniques } \\
\hline Tool /Electrode wear rate & $*$ & $*$ & $*$ & $*$ \\
\hline Surface roughness & $*$ & $*$ & $*$ & $*$ \\
\hline Electrolyte fluid velocity, m/s & - & - & - & $*$ \\
\hline Type of electrolyte used / Dielectric fluid & $*$ & - & - & $*$ \\
\hline Concentration of electrolyte & - & - & - & $*$ \\
\hline Initial interelectrode gap thickness, mm & $*$ & - & - & $*$ \\
\hline Back pressure of electrolyte & - & - & - & $*$ \\
\hline Flow rate & - & - & - & $*$ \\
\hline Pulse interval/duration & $*$ & - & $*$ & - \\
\hline Track displacement & - & - & - & $*$ \\
\hline Layer thickness & - & - & $*$ & - \\
\hline Lamp current intensity & - & - & $*$ & - \\
\hline Tool scan speed & - & - & - & $*$ \\
\hline Gas Pressure & - & - & $*$ & - \\
\hline Interval time & - & - & $*$ & - \\
\hline Power & $*$ & $*$ & $*$ & $*$ \\
\hline Slurry type & - & $*$ & - & - \\
\hline Slurry grit size & - & $*$ & - & - \\
\hline
\end{tabular}

* parameters considered; - parameters that are excluded.

the challenges of micro-EDM process can be well controlled by controlling the voltage of the process.

Table 2 shows some of the dielectric fluids that were used for EDM of titanium and its alloys. Dielectric fluids have been identified as a critical parameter that has significant influence on EDM performance [133,134]. Figure 9 shows some of these fluids and their effects on MRR, relative electrode wear rate (REWR) and surface roughness. It can be seen that the use of compound dielectric fluid containing water, tap water and 0.5 vol. $\%$ hydrogen peroxide showed higher MRR and lower tool wear in comparison with other dielectric fluids such as kerosene, EDM oil and other variants modified through silicon carbide $(\mathrm{SiC})$ or Aluminum $(\mathrm{Al})$ powder.

With moderate increase in viscosity of dielectric fluid combined with the use of rotating electrode, MRR can be improved [135].

For large scale EDM, pulse on time, and peak current are the most significant factors which affect the overall performance of the EDM process. Also, rotating electrode may increase surface roughness and high electrical discharge often induce surface defects on the surface of the titanium workpiece. Hybrid process such as integrating
USM and EDM has been reported to improve discharge efficiency, improve MRR and minimize thickness of recast layer [135].

\subsubsection{Electrochemical machining}

Electrochemical machining (ECM) is a controlled anodic dissolution process for shaping titanium and its alloys $[101,104]$. In recent times, it has received more research attention from researchers than the LBM and USM techniques. Dyaminor et al. [142] showed that it was possible to reduce the machining time of a titanium rotor cast blade for vortex pump using electrochemical machining. The machining was performed in $15-20 \% \mathrm{NaCl}$ at $20-25^{\circ} \mathrm{C}, 45-65 \mathrm{~A} \mathrm{~cm}^{2}$. A good surface finish ranked as class 6-7 was obtained but rounding of the blade edges was completed on a lathe machine.

In ECM, the choice of electrolyte has been identified as one of the critical parameters for successful machining of titanium and its alloys. Bernard [101] investigated the electrochemical machining of CP-Ti, Ti-2.5Cu, Ti-6Al-4V and $\mathrm{Ti}-4 \mathrm{Al}-4 \mathrm{Sn}-4 \mathrm{Si}$ in potassium bromide electrolytes of varying concentrations. These alloys are essentially 
Table 2. Effect of different dielectric fluids on titanium alloys under eclectic discharged machining.

\begin{tabular}{|c|c|c|c|c|}
\hline Dielectric fluids & $\begin{array}{l}\text { Powder Additives/ } \\
\text { Compositions }\end{array}$ & Alloys & Effect & Ref. \\
\hline EDM oil & $\mathrm{B}_{4} \mathrm{C}$ & Ti-6Al-4V & MRR increased; Ra reduced; and EWR increased. & {$[136]$} \\
\hline Pure water & $\mathrm{SiC}$ & Ti-6Al-4V & MRR increased; Ra reduced. & {$[138]$} \\
\hline Distilled water & - & Ti-6Al-4V & $\begin{array}{l}\text { Distilled water showed superior performance } \\
\text { in comparison with kerosene in terms of } \\
\text { improved MRR and surface finish }\end{array}$ & {$[140]$} \\
\hline Kerosene & $\mathrm{SiC}, \mathrm{Al}$ & Ti-6Al-4V & $\begin{array}{l}\mathrm{SiC} \text { mixed with kerosene offered the best MRR. } \\
\text { Using either } \mathrm{Al} \text { or } \mathrm{SiC} \text { led to inferior surface roughness }\end{array}$ & [141] \\
\hline
\end{tabular}

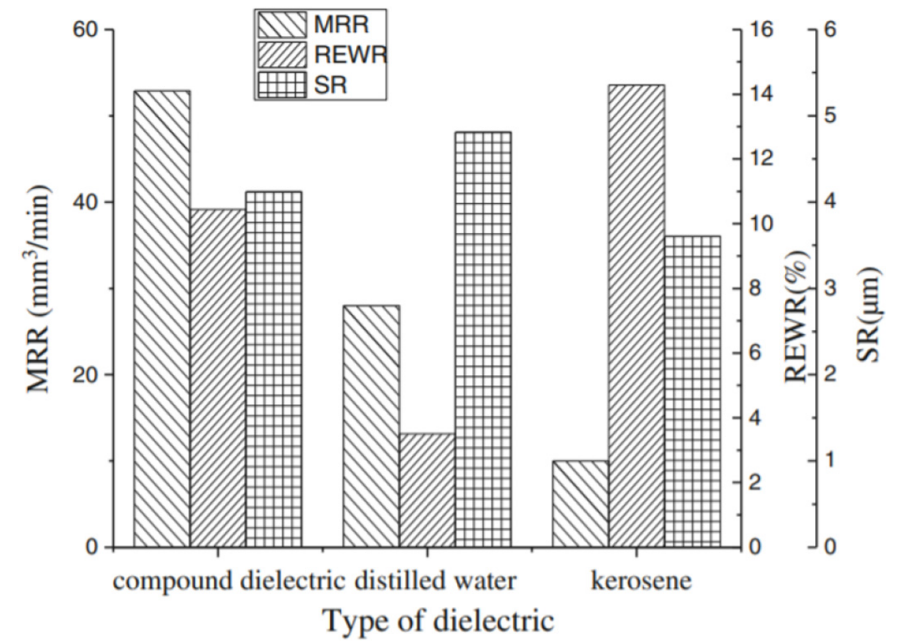

Fig. 9. Effect of dielectric fluids on MMR, REWR and surface roughness during EDM on Ti-6Al-4V, reuse with permission from Springer Nature, Wang et al. [135].

classified as $\alpha$ and $\alpha+\beta$ alloys. It was found that the materials dissolved in these solutions at the transpassive region with efficiencies greater than $100 \%$ except at low current densities where significant passivation of alloys occur, and material removal rate is depleted. The author concluded that the addition of $\mathrm{NaCl}$ to the potassium bromide solutions improved dissolution of materials at low current densities. Liu et al. [112] also showed that mirror like surface finish of machined titanium was obtained in $\mathrm{NaCl}$, but $\mathrm{NaNO}_{3}$ yielded uneven metal removal which led to poor surface finish. Davydor et al. [143] published a review article on the electrochemical machining of titanium explaining how combinations of electrolytes could help improve the effectiveness of the process. They reported that the amount of titanium in the alloys have significant influence on the choice of electrolytes to be used and the overall performance of electrochemical machining.
However, no attention was given to optimisation of other parameters that influence the effectiveness of the process. Recently, it was shown that modifying tool geometry alongside electrolyte combinations could help improve surface finish of titanium alloys machined using the ECM process. $\mathrm{Yu}$ et al. [116] studied the electrochemical machining of titanium in NaCl-ethylene glycol electrolyte. The study focused on solving the problem of electrolyte refreshment by using rotary helical electrode which facilitated easy removal of electrolysis products. Varied electrolytes were used, and results showed that $1 \mathrm{Mol} / \mathrm{L}$ $\mathrm{NaCl}$-ethylene glycol electrolyte was suitable for machining titanium with good surface finish and high precision. Optimum conditions were $11 \mathrm{~V}, 400 \mathrm{rpm}$ spindle speed, $200 \mathrm{kHz}$, electrode feed rate of $0.3 \mu \mathrm{m} / \mathrm{s}$ and duty ratio of $30 \%$.

Hizume and Natsu [144] evaluated the influence of machining parameters on ECM characteristics of titanium alloy. One major challenge they addressed was the removal of passive film formed on the machined surface at low current density. Current density varies during scanning by the tool and this causes uneven surface during machining. They showed that optimizing the voltage could help mitigate uneven surface during ECM of titanium alloys. Apart from the voltage of the ECM system, electrolyte flow is another parameter that was considered by researchers. Dhobe et al. [115] investigated the surface characteristics of titanium subjected to different velocity of electrolyte flow and voltage. They found that higher flow velocity and applied voltage increased material removal rate and the surface finish was improved. Surface roughness was within the acceptable range for biomedical implants. Titanium oxide layer was found on machined surface hence improving corrosion and chemical resistance of the titanium (CP-Ti) workpiece.

Since ECM was successfully applied on both $\alpha$ and $\alpha+\beta$ titanium alloys, some researchers considered trying the process on $\beta$ titanium alloys which are considered 
more difficult to machine using the conventional techniques. Liu et al. [112] evaluated the jet electrochemical machining (JECM) of Ti-10V-2Fe-3Al alloy. A schematic representation of the JECM process is shown in Figure 10. The alloy had poor machinability when subjected to

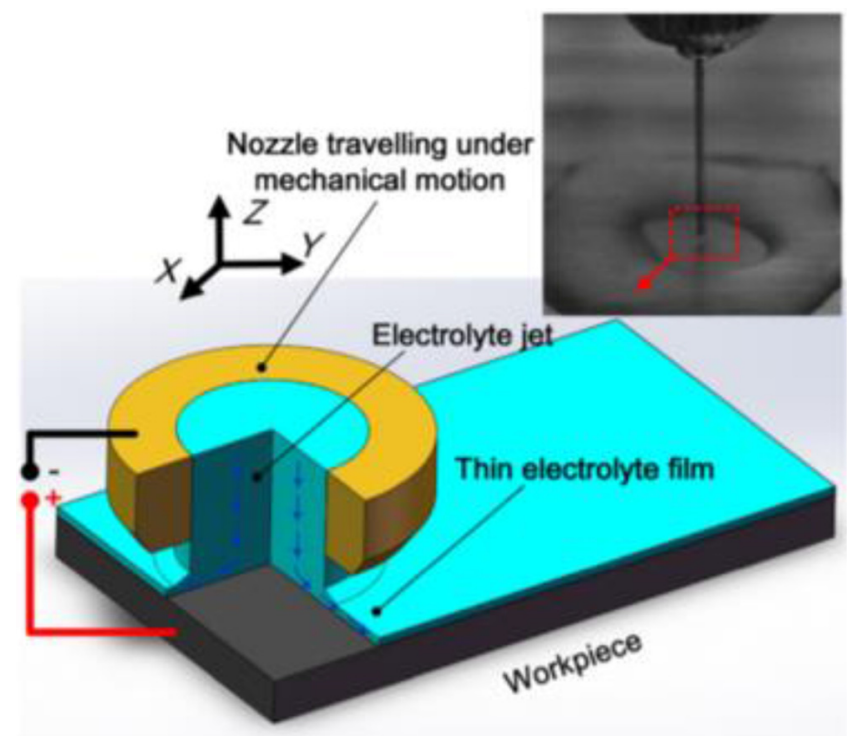

Fig. 10. Schematic representation of jet ECM process, reuse with permission from Elsevier, Liu et al. [112]. mechanical machining but was successfully machined using ECM with the optimum machining parameters being $24 \mathrm{~V}, 0.6 \mathrm{~mm}$ IEG, $2.1 \mathrm{~L} / \mathrm{mm}$ flow rate and $15 \%$ $\mathrm{NaCl}$. This combination of parameters yielded a material removal rate of $10.062 \mathrm{~g} / \mathrm{min}$. JECM allows for multidirectional flow of electrolyte and this makes it a potential process for the manufacture of $3 \mathrm{D}$ components with high dimensional accuracy. Liu et al. [118] explored the feasibility of making groove on Ti-1023 alloy (Fig. 11) using JECM. Applied voltages, IEG, electrolyte flow rate, nozzle travelling speed were varied to find the optimum process condition. It was found that $24 \mathrm{~V}, 0.6 \mathrm{~mm}$ IEG, $2.1 \mathrm{~L} / \mathrm{min}$ flow rate and $23 \mu \mathrm{m} / \mathrm{s}$ nozzle travelling rate were the optimum parameters for generating high complex surface structure on Ti-1023 alloy. Average surface roughness was $0.273 \mu \mathrm{m}$, machining occurred beyond the breakdown potential.

Similar to the EDM process, ECM could also be used to achieve machining at microscale regardless of the alloy type. Wang et al. [111] showed that the combined use of $\mathrm{NaCl}$ and $\mathrm{NaNO}_{3}$ could effectively be used for electrochemical machining of deep narrow slits on TB6 alloy. The authors developed a vibration apparatus which stabilized the process. A vibration frequency of $50 \mathrm{~Hz}$ and amplitude of $0.05 \mathrm{~m}$ yielded a max feed rate of $2.2 \mathrm{~mm} / \mathrm{min}$ and led to an excellent surface finish and efficient current distribution. Anasane and Bhattacharyya [145] assessed the fabrication of microfeatures on titanium
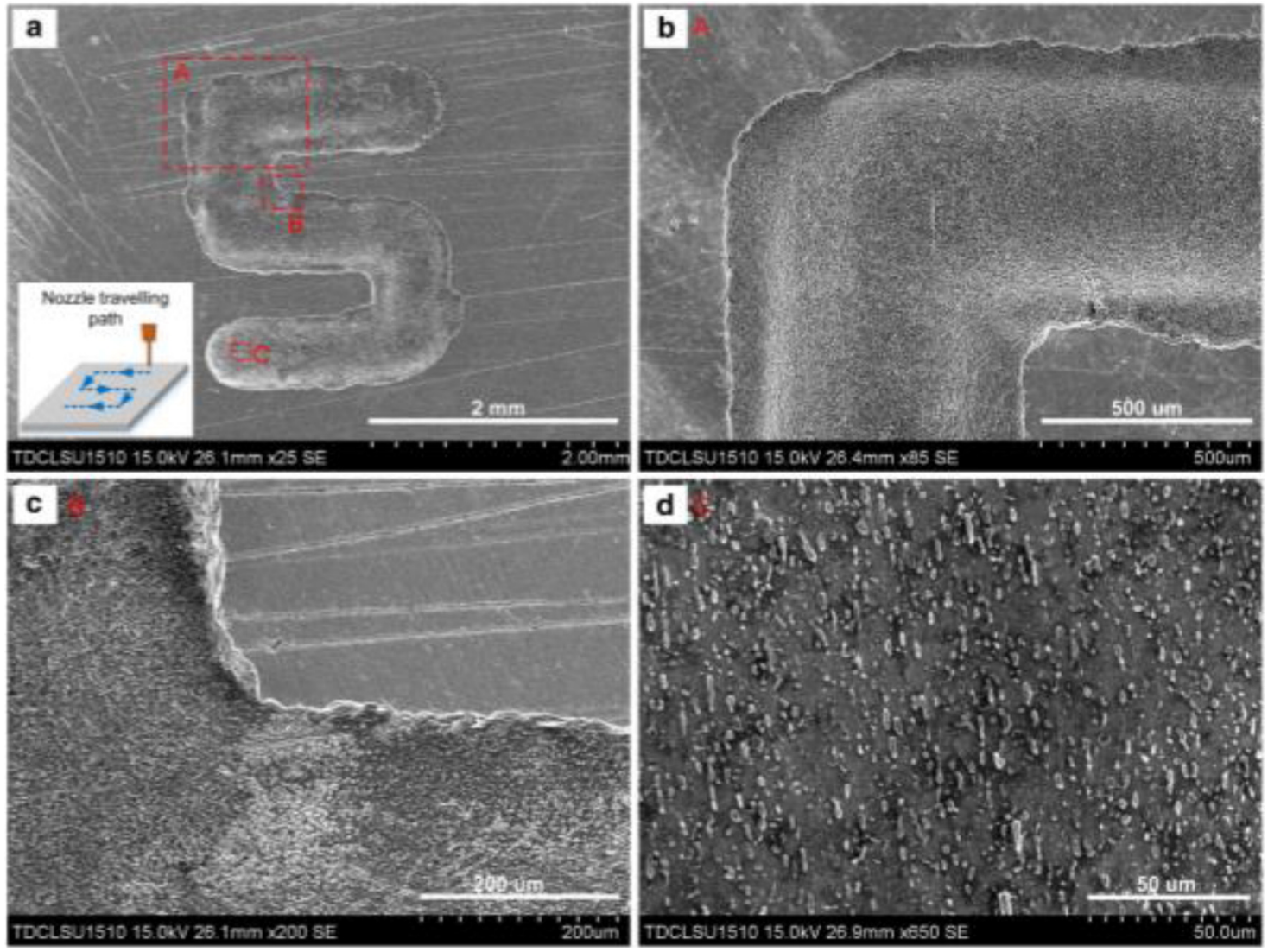

Fig. 11. SEM images showing (a) microgroove (s-shaped) feature machined by JECM with details of different marked areas (b) A, (c) B and (d) C, reprinted with permission from Elsevier, Liu et al. [112]. 


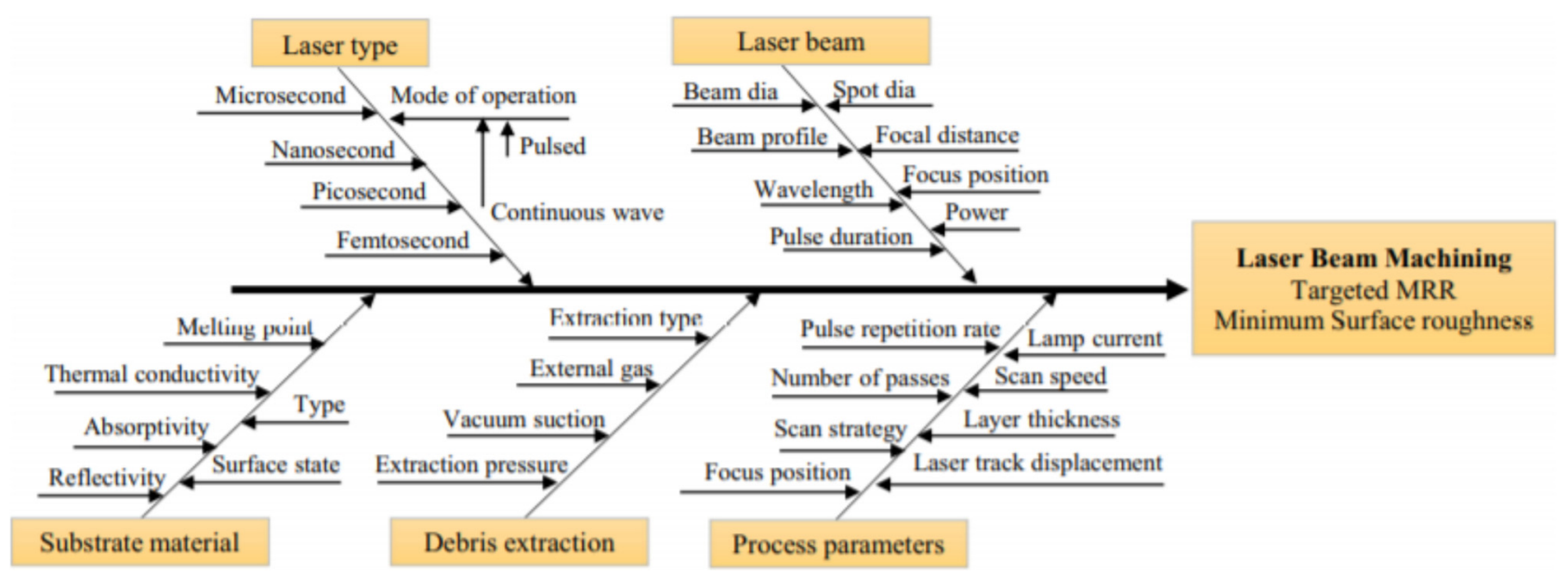

Fig. 12. Possible factors affecting beam machining performance (metal removal rate and surface roughness), reuse with permission from Springer Nature, Ahmed et al. [109].

Table 3. RSM FCCCD and the selected experimental results, reuse with permission from Springer Nature, Ahmed et al. [109].

\begin{tabular}{|c|c|c|c|c|c|c|c|c|c|}
\hline$\underline{\text { Run order }}$ & $I(\%)$ & $f(\mathrm{kHz})$ & $\mathrm{V}(\mathrm{mm} / \mathrm{s})$ & $\mathrm{TD}(\mu \mathrm{m})$ & $\mathrm{LT}(\mu \mathrm{m} / \mathrm{scan})$ & $\operatorname{MRR}_{\text {th }}\left(\mu m^{3 / 8}\right)$ & $\operatorname{MRR}_{\text {act }}\left(\mu m^{3 / 8}\right)$ & $\operatorname{MRR}(\%)$ & $R a(\mu \mathrm{m})$ \\
\hline 1 & 75 & 20 & 200 & 12 & 1 & 24.00 & 18.00 & 75 & 1.00 \\
\hline 2 & 75 & 20 & 200 & 8 & 1 & 16.36 & 20.45 & 125 & 1.13 \\
\hline 3 & 80 & 15 & 300 & 10 & 2 & 66.67 & 33.33 & 50 & 1.27 \\
\hline 4 & 75 & 10 & 400 & 8 & 1 & 30.51 & 38.14 & 125 & 1.17 \\
\hline 5 & 80 & 15 & 300 & 10 & 2 & 66.67 & 33.33 & 50 & 1.14 \\
\hline
\end{tabular}

by ECM micromachining. It was found that microtool could help reduce the voltage for anodic dissolution of titanium from typical range of $10-12 \mathrm{~V}$ to $6-7 \mathrm{~V}$. Microtool vibration could deliver a current density of $0.28-0.43 \mathrm{~A} /$ $\mathrm{mm}^{2}$ for controlled anodic dissolution of titanium alloy. At higher voltages, microtool vibration led to stray currents which caused a tapered hole. The authors recommended that insulation coating of microtools used in ECM could help improve the process and prevent the formation of tapered hole. He et al. [110] also showed that a diamond shaped hole could be generated on a TC4 titanium alloy using a multi-physical field coupling for generating vibrations assisted electrochemical machining. The vibration facilitated a reciprocating motion of the cathode tool such that insoluble matter was discharged in the surface of the titanium alloy in the processing region. The findings from these works suggest that vibration assisted ECM could potentially offer significant progress in terms of machinability of titanium alloys as already noted in vibration assisted EDM.

\subsubsection{Laser beam machining}

Prior to 2008, a few studies were carried out on laser beam machining of titanium-based alloys. The findings of these studies were captured by Dubey and Yadava [146] in their review. They reported that $\mathrm{CO}_{2}$ and Nd.YAG lasers were the most common lasers that were available. The lasers were used for machining large parts from metallic workpiece and had the potential for machining microparts. Due to limited amount of studies on micromachining using laser, they concluded that laser machining of thick workpiece for microparts need considerable amount of research work. They reported that obtaining optimum parameters for laser machining would improve machining outcomes but using single objective during optimisation may not yield the best results as improvement in one objective may affect the other objectives. Hence, they suggested that researchers should incorporate multi-objective optimisation to improve the overall performance of LBM. As at 2008, they recommended that parameters such as beam spot diameter, thermal conductivity and reflectivity of workpiece must be considered when improving laser beam machining in subsequent works. The studies carried out since the review of Debby and Yedava in 2008 [106] have considered one or more of their recommendations. For example, the machinability of Ti-6Al-4V using laser beam machining was explored by Ahmed et al. [109] in 2019. They showed that machinability indicators such as metal removal rate and surface roughness of titanium are influenced by a wide spectrum of parameters as shown in Figure 12. The parameters considered are shown in Table 3.

Of these variables, five parameters which include lamp current intensity $(I)$, pulse frequency $(f)$, scanning speed $(V)$, track displacement $(T D)$ and layer thickness $(L T)$ were varied, and their influence on material removal rate 
Table 4. Optimisation selection criteria and other details, reuse with permission from Springer Nature, Ahmed et al. [109].

\begin{tabular}{llllll}
\hline Response & Goal & Lower & Target & Upper & Fit \\
\hline MRR & Target & 0 & 100.00 & 383.33 & 100.00 \\
$\mathrm{Ra}$ & Minimum & & 0.97 & 7.75 & 0.965 \\
\hline
\end{tabular}

Table 5. Response prediction and solutions from mathematical models, reuse with permission from Springer Nature, Ahmed et al. [109].

\begin{tabular}{lllllllll}
\hline Run order & $\begin{array}{l}I \\
(\%)\end{array}$ & $\begin{array}{l}f \\
(\mathrm{kHz})\end{array}$ & $\mathrm{V}(\mathrm{mm} / \mathrm{s})$ & $\mathrm{TD}(\mu \mathrm{m})$ & $\mathrm{LT}(\mu \mathrm{m} / \mathrm{scan})$ & Ra fit & MRR fit & CD \\
\hline 1 & 75 & 10.3 & 249.58 & 12 & 1.12 & 0.965 & 100.00 & 1.000 \\
2 & 75 & 10.7 & 400 & 8.66 & 1.07 & 0.975 & 110.13 & 0.981 \\
3 & 75 & 20 & 212.18 & 8.29 & 1.06 & 0.971 & 114.98 & 0.972 \\
4 & 77.63 & 18.05 & 390.79 & 8.11 & 1.07 & 1.022 & 95.39 & 0.972 \\
5 & 75.98 & 20 & 306.95 & 8 & 1 & 0.966 & 93.18 & 0.965 \\
\hline
\end{tabular}

and surface roughness was established. The authors used MRR and surface roughness as multiple-objective functions to be optimised, they targeted a machine response of $100 \%$ MRR and surface roughness ( $\mathrm{Ra}$ ) of 0.967 as indicated in Table 4 . They noted that having absolute control of the laser beam machining such that $100 \%$ material removal rate and good surface finish are achieved per laser scan is difficult to achieve experimentally. Hence, Response Surface Method (RSM)-based face-centered central composite design (FCCCD) and analysis of variance (ANOVA) were used to optimize LBM parameters and these optimised parameters were validated experimentally. The results obtained from optimisation indicated that the targeted $100 \%$ material removal rate and $\mathrm{Ra}$ of 0.965 could be achieved when machining parameters were set to laser intensity $-75 \%$, pulse frequency $-10.33 \mathrm{~Hz}$, scanning speed $-230 \mathrm{~m} / \mathrm{s}$, track displacement $-12 \mu \mathrm{m}$ and layer thickness $-1.11 \mu \mathrm{m}$ as shown in Table 5 . The composite desirability was found to be 1.00 which suggested that the model was robust. These optimised parameters were validated experimentally and MRR was $97.75 \%$, a value that was $2.25 \%$ less than the predicted MRR, while Ra was 0.9 which was about $5 \%$ less than the model prediction.

Farasati et al. [147] in another study optimised the laser micromachining of Ti-6Al-4V using response surface methodology and analysis of variance. Taper hole and material removal rate were the multiple indicators that were used to assess machinability of the alloy, it was found that material removal rate was significantly influenced by wait time while taper hole was largely controlled by laser power and pulse frequency. Experimental verification of the optimised machining parameters showed that an error of about $10 \%$ was obtained.

In addition to laser micromachining in air, underwater laser machining of titanium alloys has been explored by some researchers. This technique reduces heat affected zones, thermally induced defects and microcracks that are associated with laser beam machining in air [148-150].

\subsubsection{Ultrasonic machining}

Ultrasonic machining was patented in 1951 by Lewis Balamuth [151]. It is a non-thermal and non-chemical process and does not cause residual stress or metallurgical changes to the workpiece. It was originally designed for machining of ceramics and other brittle materials. The process has now been successfully applied on titanium alloys. The combination of operating parameters determines relative productivity irrespective of the property of the workpiece and tool. Generally, subzero temperature is preferred to ambient and high temperatures when carrying out ultrasonic machining. Other factors that contribute to higher material removal rate is high slurry concentration and larger abrasive grits [29]. Churi et al. [113] evaluated the influence of process parameters such as feed rate, spindle speed and ultrasonic power on the cutting force, material removal rate and surface roughness. It was found that increasing feed rate and spindle speed increased the cutting force, metal removal rate and surface roughness. However, spindle speed did not have any significant effect on material removal rate. Their study showed that surface roughness decreased when ultrasonic power was increased, but it does not have any influence material removal rate. The effect of ultrasonic power on cutting force (Fig. 13) showed that below a critical ultrasonic power value of $50 \%$, the cutting force reduced. Beyond this value, cutting force increased.

Singh and Khamba [114] showed that it was possible to drill holes in titanium and its alloys without surface damage like cracking. They emphasised that hardness of the workpiece was not the criteria for obtaining high material removal rate but combined effect of composition of titanium alloys and the mechanical properties relative to the tool. Singh and Khamba [90] showed through mathematical modeling that tool wear rate in ultrasonic machining of titanium-based alloys is significantly affected by tool type (stainless steel), ultrasonic power rating $(450 \mathrm{~W})$, and slurry grit size (500 grit). Kumar and 
Khamba [42] used dimensional analysis to model material removal rate for ultrasonic machining of titanium alloy. They found that optimum MRR can be achieved by using a tool material of higher hardness (cemented carbide), higher power rating $(400 \mathrm{~W})$, coarse slurry (220 grit) and hard abrasive $\left(\mathrm{B}_{4} \mathrm{C}\right)$. The most significant parameter for obtaining higher material removal rate was power rating factor as it accounted for $42 \%$, followed by abrasive type, slurry grit size (17.2\%) and tool materials (13.2\%). Kumar [123] investigated the relationship between the surface

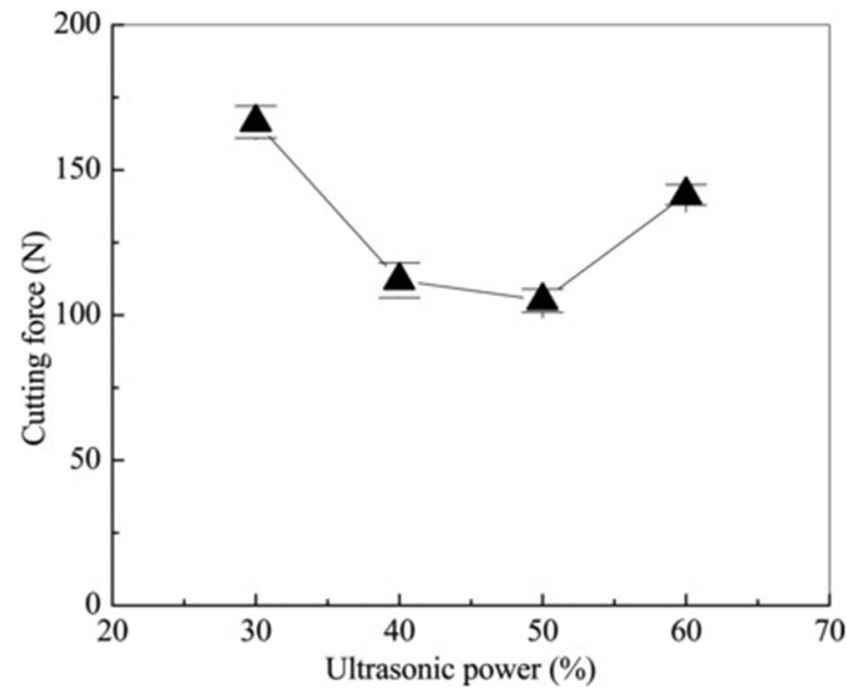

Fig. 13. Effect of ultrasonic power on cutting forces in USM, reuse with permission from Taylor and Francis, Churi et al. [113]. integrity and microhardness of ultrasonic machined CP-Ti. Figure 14 shows the cause and effect diagram that summarised the parameters considered in their study. Taguchi experimental design and ANOVA was used in optimising the USM parameters. It was found that the optimum value of surface roughness was $0.36 \mu \mathrm{m}$ when tough and ductile tool (titanium alloy), brown alumina slurry (softer) with very fine grit size of $18 \mu \mathrm{m}$ and lowest power rating of $100 \mathrm{~W}$ were used. On the microhardness of the workpiece, they established that an inverse relationship exists between microhardness and the rate of energy input in the workpiece. Hence hardness increased as rate of energy input decreased in the workpiece. ANOVA was used to determine the major factors influencing the rate of energy input; it was shown that slurry size and power rating were the two major contributors to energy input at $45 \%$ and $27.2 \%$ respectively. To reduce the time and resources involved in measuring surface roughness of machined parts, the researchers correlated the microhardness values obtained from the workpiece with the surface roughness using quadratic regression. As indicated in Figure 15, the microhardness of the workpiece after USM operation can be used to estimate the surface roughness of the workpiece.

\subsubsection{Magnetic abrasive finishing}

Magnetic abrasive finishing (MAF) is a non-conventional machining process where machining is carried out under the influence of magnetic field and magnetic abrasive particles. It was first developed in the 1930s but was only finalised in the 1960s [152]. The process has developed into a full-blown finishing process in the last 10 years [152]. Both

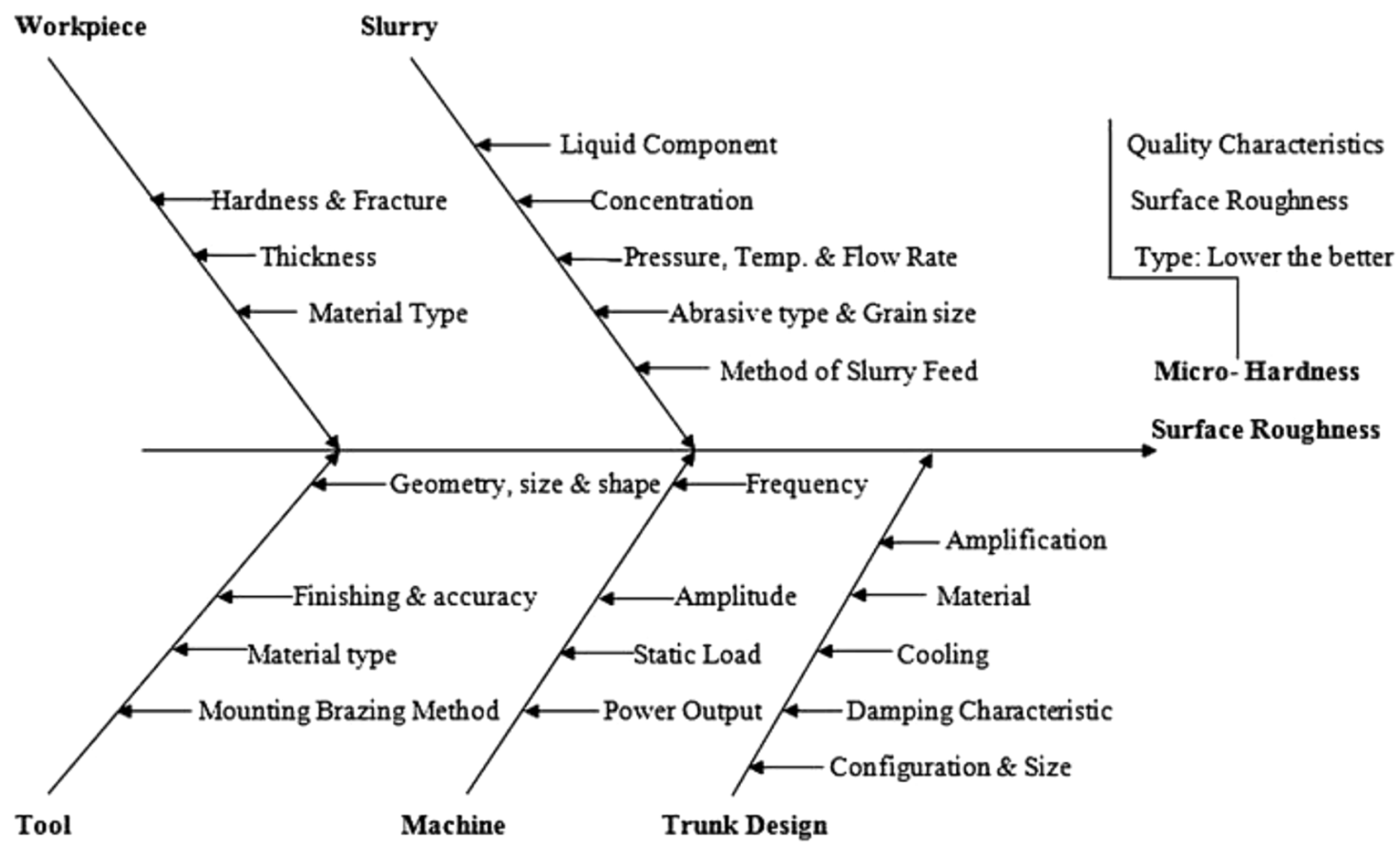

Fig. 14. Possible factors affecting ultrasonic machining performance (metal removal rate and surface roughness), reuse with permission form Springer Nature, Kumar [123]. 


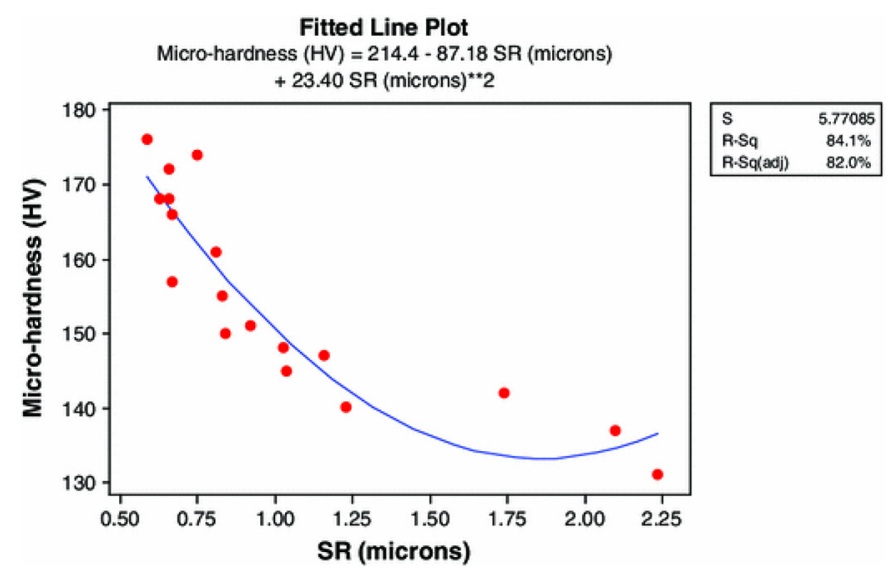

Fig. 15. Correlation between surface roughness (SR) and microhardness, reuse with permission from Springer Nature, Kumar [123].

ferrous and nonferrous metals can be machined using this process $[153,154]$. The major advantage of this process is that workpiece can be machined to obtained high quality surface finish in the nanometer range. Also, planar surface finish, cylindrical surface finish, intricate parts and finishing of other complex shaped profiles can be achieved using MAF [105,106,155]. Like other non-conventional machining process, a huge number of parameters influence MAF performance. These parameters include magnetic abrasive type, abrasive particle, magnetic device, workpiece material, working gap, grinding oil, rotational speed, finishing time and axial vibration. The most prominent machinability indicator is surface roughness although metal removal rate, removal weight and dimensional accuracy are equally measured as machining responses [152].

A brief schematic description of the MAF principle is presented in Figure 16 where magnetic brush is formed between the working gap between the magnetic poles and workpiece upon the application of magnetic field. The magnetic brush contacts the workpiece and removes the metal at the surface to obtain a fine surface finish. More detailed information on the process principles, critical parameters and limitations of this process can be found in Heng et al. [152]. The review of Heng et al. [152] did not refer to any study that involved magnetic abrasive finishing of titanium and its alloys. Since high quality surface finish is a critical requirement for high performance titanium alloys used in aerospace, automotive and biomedical industries, the different MAF approaches that researchers explored to enhance the surface finish of titanium alloys are presented in the succeeding paragraphs.

Barman and Das $[155,156]$ developed a novel magnetic polishing tool from Nd-Fe-B alloy and optimised the geometry, dimensions and configuration for the purpose of improving the surface finish of Ti-6Al-4V alloy. They designed two tool paths namely parallel and spiral paths for the MAF and evaluated the effect on surface roughness of the Ti-6Al-4V. They found that the parallel path offered the best surface finish. Surface roughness of the workpiece was reduced from $180 \mathrm{~nm}$ to $10 \mathrm{~nm}$, a $94.4 \%$ reduction. The optimum parameters which influenced this
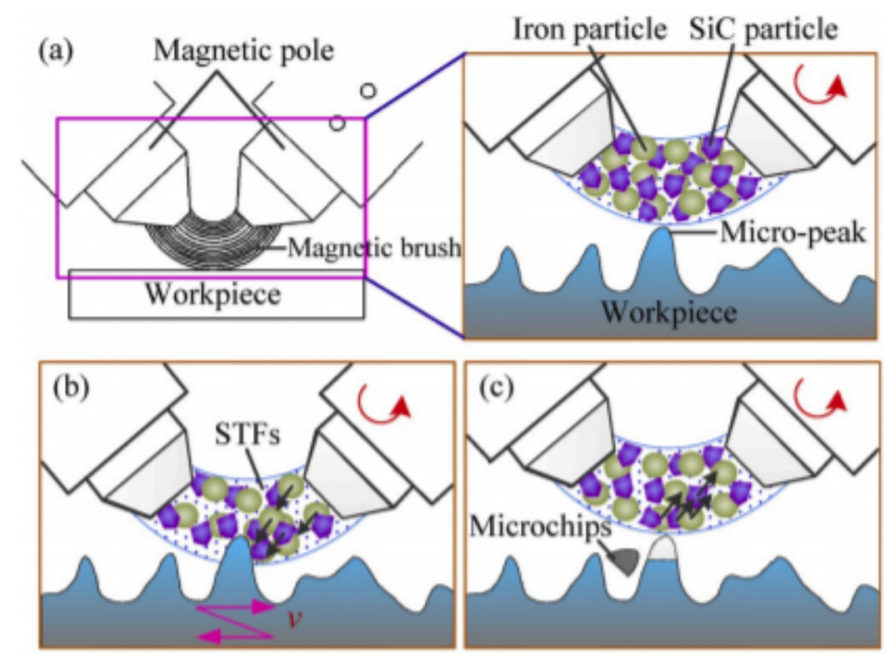

Fig. 16. Schematic representation of MAF, (a) magnetic brush is formed once magnetic field is applied between the magnetic poles; (b) magnetic brush contacts the micro-peak at the surface of the workpiece; and (c) the surface peak is removed. Reuse with permission from Elsevier, Fan et al. [158].

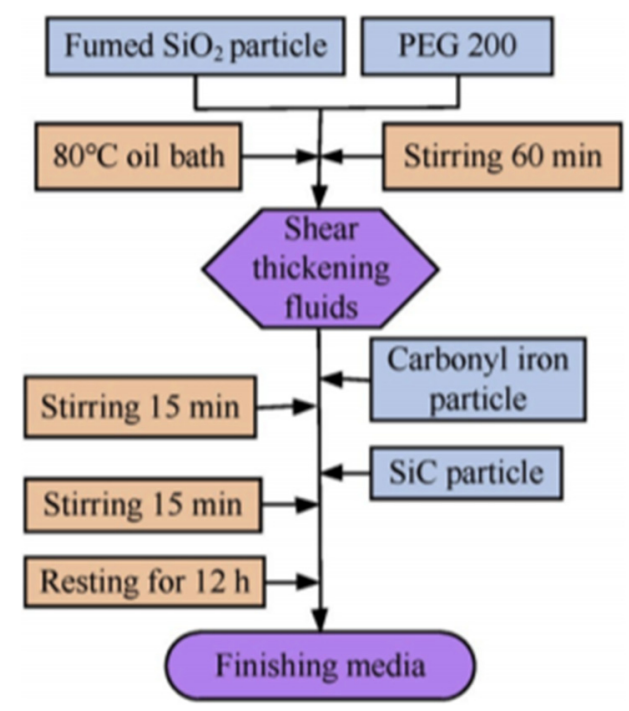

Fig. 17. Flow chat describing the preparation of MAF finishing media, reuse with permission from Elsevier, Fan et al. [158].

result were tool speed of $12000 \mathrm{rpm}, 1 \mathrm{~mm}$ working gap and 6.30 hours finishing time.

Burman and Das [157] showed that Ti-6Al-4V implant to be used for femoral knee joint can be polished to the required $3 \mathrm{D}$ surface finish using magnetic field assisted finishing process. The optimum parameters for achieving the surface roughness in the nanometer range of $5-16 \mathrm{~nm}$ were tool speed of $901 \mathrm{rpm}, 0.6 \mathrm{~mm}$ working gap and 4.30 finishing time.

Fan et al. [158] developed a finishing media containing a combination of shear thickening fluid, carbonyl iron $(250 \mu \mathrm{m})$ and silicon carbide $(150 \mu \mathrm{m})$ particles as illustrated in Figure 17. The finishing media was used to 
enhance MAF of Ti- $6 \mathrm{Al}-4 \mathrm{~V}$ workpiece. The finishing media contained different concentrations $(10 \%, 15 \%, 17 \%$ and $20 \%$ ) of the shear thickening fluid. The surface roughness of the workpiece was reduced from $1.57 \mu \mathrm{m}$ to $54 \mathrm{~nm}$ representing an improvement of $95 \%$ in surface finish. The optimum parameters that was used to achieve this improvement were feed rate of $15000 \mathrm{~mm} / \mathrm{min}$, spindle rotational feed of $900 \mathrm{rpm}, 15 \%$ shear thickening fluid and $0.8 \mathrm{~mm}$ working gap. Li et al. [159] showed that the shape of the magnetic head had significant influence on the performance of MAF when used for surface polishing of $1 \mathrm{~mm}$ Ti-6Al-4V wire. They investigated different taper angles $\left(0,25,35^{\circ}\right)$ and found that at taper angle of $37^{\circ}$, tool speed of $800 \mathrm{rpm}$, processing time of $300 \mathrm{~s}$ and abrasive particle size of $178 \mu \mathrm{m}$, the surface roughness of $1 \mathrm{~mm}$ Ti-6Al-4V wire was reduced to $0.28 \mu \mathrm{m}$ from $0.9 \mu \mathrm{m}$.

Similar to the EDM process, MAF can be improved by incorporating ultrasonic vibration or electrolytic assistance $[153,160]$. These hybrid machining methods have been applied mostly on steel, but Zhou et al. [160] reported that the surface integrity and fatigue strength of titanium part can be improved using ultrasonic magnetic abrasive finishing. They found that surface roughness reduced from 1.38 to $0.4 \mu \mathrm{m}$. Also, the tensile stress of a milled titanium part changed from $280 \mathrm{MPa}$ to compressive $20 \mathrm{MPa}$ after ultrasonic magnetic abrasive finishing.

\subsubsection{Summary of non-conventional machining processes}

From these studies, more parameters are involved during non-conventional machining operations in comparison with the conventional machining. Despite this, for each technique, researchers have established the critical parameters that have major influence on the metal removal rate and surface roughness for the different machining techniques. Although most of these studies have focused on Ti-6Al-4V alloy, the non-conventional machining techniques have been used to successfully machine some $\alpha+\beta$ and $\beta$ titanium alloys that are reportedly more difficult-to-machine using the conventional techniques. This suggests that alloy chemistry may not significantly cause difficulty when adopting these techniques in machining a wide range of titanium alloys. Only a few studies on these techniques focused on electrode or tool wear, this suggests that tool wear rate in is not a major concern in most of these techniques as the case would be in conventional machining operations. There is no direct evidence indicating that these techniques increase production rate, but ability to control material removal rate without significant degradation of tool suggest that waste generation from machining process could be lesser than in conventional machining. Rapid tool wear which is common in some conventional machining contributes to the volume of waste generated and high cost of machining. Also, poor surface finish resulting from damaged tool contributes to waste incurred from the conventional machining process. Hence, non-conventional techniques may offer cost effectiveness in machining of titanium and its alloys, but this must be investigated to ascertain this claim.

\subsection{Comparing conventional and non-conventional machining techniques}

From the results presented in the articles considered in this review, it was difficult to compare the various machinability indicators obtained from conventional and nonconventional machining techniques. This is because researchers explored different machining conditions even for the same alloy and machining technique. Furthermore, the machinability indicators for the broad categories of machining techniques differ to some extent. For example, conventional machining techniques reported mostly on chip formation, cutting forces and tool life while nonconventional techniques reported on metal removal rate and electrode wear rate for techniques where electrodes are used. The only machinability indicator that is prominent in both categories of machining techniques is surface roughness. Hence, in this section, we compare the performance of conventional and non-conventional machining techniques using surface roughness as a criterion. Table 6 present the surface roughness of different machining techniques obtained at the different optimum machining conditions for different alloys. We note that except for ultra-precision machining and magnetic abrasive machining, the surface roughness values of the alloys were in the micrometer range $(0.7-4.22 \mu \mathrm{m})$ regardless of the category of machining techniques. It is unclear which machining technique will be more affordable if a targeted surface roughness value is to be achieved. It is the opinion of the authors that research in this direction may help provide insights into cost reduction of titanium machining. UPM and MAF, although they belong to different category of machining techniques, they offer very fine surface finish in the nanometer range. Therefore, researchers may consider studying which of these techniques is affordable should a target of $10 \mathrm{~nm}$ surface roughness be set. Similar approach can be applied to other machinability indicators. Tool wear rate can be set as targeted criterion for comparing machining techniques and determining the most effective in terms of cost, performance and versatility.

\section{Summary and future directions}

Titanium based alloys are difficult-to-machine, hence their components are highly priced. The challenges associated with titanium machining include high rate of tool wear, poor surface finish of workpiece, high energy consumption, low productivity during manufacturing and high rate of waste generation from machined workpiece. These challenges have been ascribed to low thermal conductivity, low modulus of elasticity, high temperature strength and chemical composition of titanium alloys. The machining techniques used for the manufacturing of titanium-based components were reviewed and classified based on contact between the workpiece and tool. The first category of machining is the conventional machining operations which involve contact between the workpiece and the tool, while the second category are non-contact machining processes or non-conventional machining techniques. The conventional operations are essentially milling, drilling and 
Table 6. Surface roughness as a function of conventional and non-conventional machining techniques.

\begin{tabular}{lllll}
\hline Machining Techniques & Category & Alloys & Surface roughness $(\mu \mathrm{m})$ & Ref. \\
\hline Fiber laser micro machining & Conventional & Ti-6Al-4V & 4.22 & {$[45]$} \\
Laser-assisted machining & Conventional & Ti5553 & 1.83 & {$[52]$} \\
Turning machining (Wet) & Conventional & Ti-6Al-4V & 1.83 & {$[10]$} \\
Machining /MQCL & Conventional & Ti-6Al-4V & 0.80 & {$[68]$} \\
Ultra-precision machining & Conventional & Ti-6Al-4V & $0.014(14 \mathrm{~nm})$ & {$[43]$} \\
Ultra-precision machining & Conventional & Ti-6Al-4V & $0.017(17 \mathrm{~nm})$ & {$[51]$} \\
Wire electric discharge machining & Non-conventional & CP-Ti; Grade 2 & 2.48 & {$[122]$} \\
Electrical discharge machining & Non-conventional & Ti-6Al-4V & 3.00 & {$[161]$} \\
Electrical discharge machining & Non-conventional & CP-Ti; Grate 2 & 2.96 & {$[162]$} \\
Laser beam machining & Non-conventional & Ti-6Al-4V & 2.37 & {$[109]$} \\
Jet electrochemical machining & Non-conventional & TB6 & 0.78 & {$[118]$} \\
Jet electrochemical machining & Non-conventional & TB6 & 0.23 & {$[112]$} \\
Jet electrochemical machining & Non-conventional & Ti1023 & 0.27 & {$[118]$} \\
Electrochemical machining & Non-conventional & TB6 & 0.75 & {$[111]$} \\
Electrochemical machining (ECM) & Non-conventional & Pure titanium & 2.40 & {$[115]$} \\
Magnetic abrasive finishing & Non-conventional & Ti-6Al-4V & $0.010(10 \mathrm{~nm})$ & {$[155]$} \\
Magnetic abrasive finishing & Non-conventional & Ti-6Al-4V & $0.054(54 \mathrm{~nm})$ & {$[158]$} \\
\hline
\end{tabular}

turning, while the non-conventional processes are electrical discharge machining, laser beam machining, electrochemical machining, ultrasonic machining and magnetic abrasive finishing. Tool wear rate, cutting forces, chip formation and surface roughness are the typical machineability indicators that are evaluated in the conventional machining techniques, while material removal rate and surface roughness are the major machinability indicators that are measured in non-conventional machining techniques. Although researchers provided optimum parameters for achieving the machinability indicators in both categories of machining techniques, it was obvious that critical parameters for obtaining good machinability is only specific to a type of operation or alloy. Some of the notable findings reported on the improvement of machinability of titanium alloys for the two categories of machining techniques are stated as follows:

- In conventional machining, lubrication and cooling are essential for improved machinability. The use of MQCL has been found to be effective in reducing cutting forces, improve tool life, enhance surface finish of titanium workpiece and reduce environmental pollution.

- Combining MQCL with cryogenic cooling of cutting tool or adding nano-sized solid lubricants like graphite, alumina and boron carbide could further enhance machinability of titanium alloys. However, this approach is considered expensive.

- Carbide tools remain the most preferred cutting tool for machining titanium alloys. The performance of these tools may be enhanced through coating to improve machinability outcomes.

- Intermittent cutting and electro-pulse treatment in ultra-precision machining are effective in obtaining very fine surface finish in the nanometer range.
- In non-conventional machining, EDM and ECM are the most investigated techniques. The choice of dielectric fluid and electrolyte play significant role in achieving good machinability in EDM and ECM respectively.

- In EDM, compound dielectric fluid has been noted to have superior performance over other dielectric fluids such as EDM oil, kerosene, distilled water and other variants which has alumina, silicon carbide and boron carbide as solid additives.

- In ECM, $\mathrm{NaCl}$ electrolyte has been found to be more effective in improving machining outcomes. However, the flow velocity and flow direction of the electrolytes must be optimised.

- The type and size of abrasive particles have significant effect on machining outcomes during USM of titanium alloys. Selecting the preferred abrasive particles depends on alloy chemistry.

- There is limited amount of studies on MAF of titanium alloys in comparison with other non-conventional techniques, however a very fine surface finish in the nanometer range can be obtained. The shape of the magnetic head and developing novel finishing abrasive media have significant influence on surface finish of the workpiece.

- Hybrid machining techniques such as USM-EDM, Ultrasonic-MAF are generally reported to offer superior machinability in comparison with the individual techniques.

Despite the above improvements, this review revealed that there was insufficient evidence to conclude that increased productivity and cost reduction could be attained using either of the conventional and nonconventional machining techniques. Therefore, future research directions should consider the following: 
- Machinability of titanium alloys is sensitive to alloy composition and results have shown that optimised parameters for machining are only valid for alloy type and specific machining operation. Ti-6Al-4V alloy has dominated the research conducted on machining of titanium and its alloys, other commercial and experimental alloys should be considered more in future work to allow for comparison of results.

- Due to large number of variables involved in machining of titanium alloys, research methods are designed to include coupled computational and experimental approach to minimize both research and manufacturing cost. The research designs often entail either Taguchi experimental design or full factorial design, finite element modeling, statistical analysis, artificial neural networks and experimental validation. Despite these efforts, it is difficult to compare machining outcomes because of the disparities between the parameters investigated. It is recommended that existing data should be used to standardize the range of parameters to be investigated by researchers in the future. This will allow easy comparison of results reported in literatures as well as easy comprehension of the new developments in machining of titanium alloys.

- Some studies should focus on cost evaluation and comparative analyses between machining techniques using machinability indicators as targets. These studies would reveal machining techniques that offer the best performance in terms of cost effectiveness and increased production rate for targeted machinability indicators.

\section{Supplementary Material}

Supplementary Table S1. Conventional machining operations with parameters.

Supplementary Table S2. Non-conventional machining techniques.

The Supplementary Material is available at https://doi. org/10.1051/mfreview/2020029.

Acknowledgements. This work was supported through the AESARISE Fellowship Programme [ARPDF 18-03], African Materials Science and Engineering Network (A Carnegie-IAS RISE network) and the DST-NRF Centre of Excellence in Strong Materials. AESA-RISE is an independent funding scheme of the African Academy of Sciences (AAS) implemented with the support of Carnegie Corporation of New York. At The AAS, AESA-RISE is implemented through AESA, the Academy's agenda and programmatic platform, created in collaboration with the African Union Development Agency (AUDA-NEPAD). The views expressed in this publication are those of the author(s) and not necessarily those of the AAS, AUDA-NEPAD or Carnegie Corporation.

\section{References}

1. C. Leyens, M. Peters, Titanium and titanium alloys: fundamentals and application, Wiley-VCH, Germany, 2003
2. M.O. Bodunrin, J.A. Omotoyinbo, Development of low-cost titanium alloys: a chronicle of challenges and opportunities. Mater. Today Proc. (2020) https://doi.org/10.1016/j.matpr. 2020.02.978

3. S.A. Niknam, R. Khettabi, V. Songmene, Machinability and machining of titanium alloys: a review. In: J.P. Davim, editor. Mach. Titan. Alloys, Springer, Berlin, Heidelberg 2014, pp. $1-30$

4. C. Veiga, J.P. Davim, A.J.R. Loureiro, Review on machinability of titanium alloys: the process perspective, Rev. Adv. Mater. Sci. 34 (2013) 148-164

5. X. Liang, Z. Liu, B. Wang, State-of-the-art of surface integrity induced by tool wear effects in machining process of titanium and nickel alloys: a review, Measurement 132 (2019) 150-181

6. E.O. Ezugwu, Z.M. Wang, Titanium alloys and their machinability - a review, J. Mater. Process Technol. 68 (1997) 262-274

7. S.H. You, J.H. Lee, S.H. Oh, A study on cutting characteristics in turning operations of titanium alloy used in automobile, Int. J. Precis. Eng. Manuf. 20 (2019) 209-216

8. R.S. Revuru, N.R. Posinasetti, V.R. Vsn, Application of cutting fluids in machining of titanium alloys - a review, Int. J. Adv. Manuf. Technol. 91 (2017) 2477-2498

9. Z. Ren, S. Qu, Y. Zhang, F. Sun, X. Li, C. Yang, Machining performance of $\mathrm{PCD}$ and $\mathrm{PCBN}$ tools in dry turning titanium alloy Ti-6Al-0.6Cr-0.4Fe-0.4Si-0.01B, Int. J. Adv. Manuf. Technol. 102 (2019) 2649-2661

10. R.S. Revuru, J.Z. Zhang, N.R. Posinasetti, T. Kidd, Optimization of titanium alloys turning operation in varied cutting fluid conditions with multiple machining performance characteristics, Int. J. Adv. Manuf. Technol. 95 (2018) 1451-1463

11. N.S. Weston, M. Jackson, FAST-forge - a new cost-effective hybrid processing route for consolidating titanium powder into near net shape forged components, J. Mater. Process. Technol. 243 (2017) 335-346

12. SAmaterials. Why Titanium is So Expensive. Stanf Adv Mater 2014. https://samaterials.wordpress.com/2014/07/ 29/why-titanium-is-so-expensive/ (accessed October 22, 2016)

13. N.S. Weston, M. Jackson, FAST-forge of titanium alloy Swarf: a solid-state closed-loop recycling approach for aerospace machining waste, Metals 10 (2020) 296

14. L. Bolzoni, E. Herraiz, E.M. Ruiz-Navas, E. Gordo, Study of the properties of low-cost powder metallurgy titanium alloys by 430 stainless steel addition, Mater. Des. 60 (2014) 628-636

15. L. Bolzoni, E.M. Ruiz-Navas, E. Gordo, Understanding the properties of low-cost iron-containing powder metallurgy titanium alloys, Mater. Des. 110 (2016) 317-323

16. P.G. Esteban, L. Bolzoni, E.M. Ruiz-Navas, E. Gordo, PM processing and characterisation of $\mathrm{Ti}-7 \mathrm{Fe}$ low cost titanium alloys, Powder Metall. 54 (2011) 242-252

17. J. Pope, M. Jackson, FAST-forge of diffusion bonded dissimilar titanium alloys: a novel hybrid processing approach for next generation near-net shape components, Metals 9 (2019) 654

18. J.J. Pope, E.L. Calvert, N.S. Weston, M. Jackson, FASTDB: a novel solid-state approach for diffusion bonding dissimilar titanium alloy powders for next generation critical components, J. Mater. Process. Technol. 269 (2019) 200-207 
19. M.K. Gupta, P.K. Sood, V.S. Sharma, Machining parameters optimization of titanium alloy using response surface methodology and particle swarm optimization under minimum-quantity lubrication environment, Mater. Manuf. Process 31 (2016) 1671-1682

20. S. Vijay, V. Krishnaraj, Machining parameters optimization in end milling of Ti-6Al-4V, Proc. Eng. 64 (2013) 1079-1088

21. S. Kumar, A. Batish, R. Singh, T.P. Singh, A hybrid Taguchi-artificial neural network approach to predict surface roughness during electric discharge machining of titanium alloys, J. Mech. Sci. Technol. 28 (2014) 2831-2844

22. K. Gupta, R.F. Laubscher, Sustainable machining of titanium alloys: a critical review, Proc. Inst. Mech. Eng. Part B 231 (2017) 2543-2560

23. M. Rahman, Z.-G. Wang, Y.-S. Wong, A Review on highspeed machining of titanium alloys, JSME Int. J. Ser. C 49 (2006) 11-20

24. V. Gupta, B. Singh, R.K. Mishra, Machining of titanium and titanium alloys by electric discharge machining process: a review, Int. J. Mach. Mach. Mater. 22 (2020) 99

25. J.E. Abu Qudeiri, A.-H.I. Mourad, A. Ziout, M.H. Abidi, A. Elkaseer, Electric discharge machining of titanium and its alloys: review, Int. J. Adv. Manuf. Technol. 96 (2018) 1319-1339

26. Y. Natarajan, P.K. Murugesan, M. Mohan, S.A. Liyakath, A. Khan, Abrasive water jet machining process: a state of art of review, J. Manuf. Process. 49 (2020) 271-322

27. A.K. Singh, D.P.S. Rao, A review on ultrasonic machining of titanium alloys, International Journal of Research and Scientific Innovation (IJRSI) 7 (2018) 81-87

28. N. Singh, P.S. Bharti, A review on micro electric discharge machining of titanium alloys, Mater. Today Proc. (2019), https://doi.org/10.1016/j.matpr.2019.08.235

29. R. Singh, J.S. Khamba, Ultrasonic machining of titanium and its alloys: a review, J. Mater. Process. Technol. 173 (2006) 125-135

30. R.R. Boyer, Titanium for aerospace: Rationale and applications, Adv. Perform. Mater. 2 (1995) 349-368

31. R.R. Boyer, An overview on the use of titanium in the aerospace industry, Mater. Sci. Eng. A 213 (1996) 103-114

32. O. Hatt, Z. Lomas, M. Thomas, M. Jackson, The effect of titanium alloy chemistry on machining induced tool crater wear characteristics, Wear 408-409 (2018) 200-207

33. O. Hatt, P. Crawforth, M. Jackson, On the mechanism of tool crater wear during titanium alloy machining. Wear 374-375 (2017) 15-20

34. M. Niinomi, Recent research and development in titanium alloys for biomedical applications and healthcare goods, Sci. Technol. Adv. Mater. 4 (2003) 445-54

35. H.J. Rack, J.I. Qazi, Titanium alloys for biomedical applications, Mater. Sci. Eng. C 26 (2006) 1269-1277

36. L.-C. Zhang, L.-Y. Chen, A Review on Biomedical Titanium Alloys: Recent Progress and Prospect, Adv. Eng. Mater. 21 (2019) 1801215

37. Yu.B. Egorova, S.V. Skvortsova, R.A. Davydenko, N.G. Mitropol'skaya, Methods for improving the effectiveness of machining of titanium and its alloys, Inorg. Mater. Appl. Res, 4 (2013) 46-51

38. J.D. Kechagias, K.-E. Aslani, N.A. Fountas, N.M. Vaxevanidis, D.E. Manolakos, A comparative investigation of Taguchi and full factorial design for machinability prediction in turning of a titanium alloy, Measurement 151 (2020) 107213
39. V.F. Pegashkin, V.I. Golubev, V.V. Medison, Use of electrical insulation of the cutting tool to increase tool life when machining titanium alloys, Int. J. Adv. Manuf. Technol. 74 (2014) 599-614

40. N. Varote, S.S. Joshi, Microstructural Analysis of Machined Surface Integrity in Drilling a Titanium Alloy, J. Mater. Eng. Perform. 26 (2017) 4391-4401

41. F. Hojati, A. Daneshi, B. Soltani, B. Azarhoushang, D. Biermann, Study on machinability of additively manufactured and conventional titanium alloys in micro-milling process, Precis. Eng. 62 (2020) 1-9

42. J. Kumar, J.S. Khamba, Modeling the material removal rate in ultrasonic machining of titanium using dimensional analysis, Int. J. Adv. Manuf. Technol. 48 (2010) 103-119

43. W.S. Yip, S. To, Sustainable Ultra-Precision Machining of Titanium Alloy Using Intermittent Cutting, Int. J. Precis. Eng. Manuf. -Green. Technol. 7 (2020) 361-373

44. J. Sun, Y.B. Guo, Material flow stress and failure in multiscale machining titanium alloy Ti-6Al-4V, Int. J. Adv. Manuf. Technol. 41 (2009) 651-659

45. A. Pramanik, Problems and solutions in machining of titanium alloys, Int. J. Adv. Manuf. Technol. 70 (2014) 919-928

46. S. Yang, G. Zhu, J. Xu, Y. Fu, Tool wear prediction of machining hydrogenated titanium alloy Ti6Al4V with uncoated carbide tools, Int. J. Adv. Manuf. Technol. 68 (2013) 673-682

47. M. Aramesh, H.M. Attia, H.A. Kishawy, M. Balazinski, Observation of a unique wear morphology of $\mathrm{cBN}$ inserts during machining of titanium metal matrix composites (Ti-MMCs); leading to new insights into their machinability, Int. J. Adv. Manuf. Technol. 92 (2017) 519-530

48. U. Heisel, M. Lutz, D. Spath, R. Wassmer, U. Walter, Application of Minimum Quantity Cooling Lubrication Technology in Cutting Processes 6 (1994)

49. K.-H. Park, M.A. Suhaimi, G.-D. Yang, D.-Y. Lee, S.-W. Lee, P. Kwon, Milling of titanium alloy with cryogenic cooling and minimum quantity lubrication (MQL), Int. J. Precis. Eng. Manuf. 18 (2017) 5-14

50. S. Pervaiz, S. Anwar, I. Qureshi, N. Ahmed, Recent Advances in the Machining of Titanium Alloys using Minimum Quantity Lubrication (MQL) Based Techniques, Int. J. Precis. Eng. Manuf. -Green. Technol. 6 (2019) 133-145

51. Y. Lou, H. Wu, Improving machinability of titanium alloy by electro-pulsing treatment in ultra-precision machining, Int. J. Adv. Manuf. Technol. 93 (2017) 2299-2304

52. T. Braham, Bouchnak, G. Germain, A. Morel, J.L. Lebrun, The influence of laser assistance on the machinability of the titanium alloy Ti555-3, Int. J. Adv. Manuf. Technol. 68 (2013) 2471-2481

53. U. Kumar, P. Senthil, A comparative machinability study on titanium alloy Ti-6Al-4V during dry turning by cryogenic treated and untreated condition of uncoated WC inserts, Mater. Today Proc. (2019) S2214785319333644

54. D. Biermann, H. Abrahams, M. Metzger, Experimental investigation of tool wear and chip formation in cryogenic machining of titanium alloys, Adv. Manuf. 3 (2015) 292-299

55. Q. An, J. Chen, Z. Tao, W. Ming, M. Chen, Experimental investigation on tool wear characteristics of PVD and CVD coatings during face milling of $\mathrm{Ti} 6242 \mathrm{~S}$ and Ti-555 titanium alloys, Int. J. Refract. Met. Hard. Mater. 86 (2020) 105091 
56. D. Bai, J. Sun, W. Chen, T. Wang, Wear mechanisms of WC/Co tools when machining high-strength titanium alloy TB6 (Ti-10V-2Fe-3Al), Int. J. Adv. Manuf. Technol. 90 (2017) 2863-2874

57. T. Li, T. Shi, Z. Tang, G. Liao, J. Han, J. Duan, Temperature monitoring of the tool-chip interface for PCBN tools using built-in thin-film thermocouples in turning of titanium alloy, J. Mater. Process. Technol. 275 (2020) 116376

58. J. Kertesz, R.J. Pryor, D.W. Richerson, R.A. Cutler, Machining Titanium Alloys with Ceramic Tools, JOM 40 (1988) 50-51

59. S. Pervaiz, I. Deiab, B. Darras, Power consumption and tool wear assessment when machining titanium alloys, Int. J. Precis. Eng. Manuf. 14 (2013) 925-936

60. K.A. Osman, Ü.H.Ö. nver, U. Seker, Application of minimum quantity lubrication techniques in machining process of titanium alloy for sustainability: a review, Int. J. Adv. Manuf. Technol. 100 (2019) 2311-2332

61. R. Evans, 2 - Selection and testing of metalworking fluids. In: V. P. Astakhov, S. Joksch, editors. Metalwork. Fluids MWFs Cut. Grind., Woodhead Publishing; 2012, p. 23-78

62. M. Namb, D. Paulo, Influence of Coolant in Machinability of Titanium Alloy (Ti-6Al-4V), J. Surf. Eng. Mater. Adv. Technol. 1 (2011) 9-14

63. T.B. Bouchnak, Etude du comportement en sollicitations extrêmes et de l'usinabilite d'un nouvel alliage de titane aeronautique: le ti555-3. phdthesis, Arts et Métiers ParisTech, 2010

64. Y. Ayed, G. Germain, High-pressure water-jet-assisted machining of Ti555-3 titanium alloy: investigation of tool wear mechanisms, Int. J. Adv. Manuf. Technol. 96 (2018) 845-856

65. M. Vosough, V. Kalhori, P. Liu, I. Svenningsson, Influence of high pressure water-jet assisted turning on surface residual stresses on Ti-6AL-4V alloy by measurement and finite element simulation, 2004, p. 107-113

66. M. Vosough, F. Schultheiss, M. Agmell, J.-E. Ståhl, A method for identification of geometrical tool changes during machining of titanium alloy Ti6Al4V, Int. J. Adv. Manuf. Technol. 67 (2013) 339-348

67. Y. Ayed, C. Robert, G. Germain, A. Ammar, Development of a numerical model for the understanding of the chip formation in high-pressure water-jet assisted machining, Finite. Elem. Anal. Des. 108 (2016) 1-8

68. S. Pervaiz, A. Rashid, I. Deiab, C.M. Nicolescu, An experimental investigation on effect of minimum quantity cooling lubrication (MQCL) in machining titanium alloy (Ti6Al4V), Int. J. Adv. Manuf. Technol. 87 (2016) 1371-1386

69. S. Ganguli, S.G. Kapoor, Improving the performance of milling of titanium alloys using the atomization-based cutting fluid application system, J. Manuf. Process 23 (2016) 29-36

70. K.-H. Park, G.-D. Yang, M.-G. Lee, H. Jeong, S.-W. Lee, D. Y. Lee, Eco-friendly face milling of titanium alloy, Int. J. Precis. Eng Manuf. 15 (2014) 1159-1164

71. Pervaiz, et al. - 2016 - An experimental investigation on effect of minimum.pdf n.d.

72. X. Qin, L. Gui, H. Li, B. Rong, D. Wang, H. Zhang, et al. Feasibility Study on the Minimum Quantity Lubrication in High-Speed Helical Milling of Ti-6Al-4V, J. Adv. Mech. Des. Syst. Manuf. 6 (2012) 1222-1233
73. G. Le, Coz, M. Marinescu, A. Devillez, D. Dudzinski, L. Velnom, Measuring temperature of rotating cutting tools: Application to MQL drilling and dry milling of aerospace alloys, Appl. Therm. Eng. 36 (2012) 434-441

74. A.K. Parida, K. Maity, FEM and experimental analysis of thermal assisted machining of titanium base alloys, Measurement 152 (2020) 107292

75. H.B. Wu, S. To, Effects of electropulsing treatment on material properties and ultra-precision machining of titanium alloy, Int. J. Adv. Manuf. Technol. 82 (2016) 2029-2036

76. S. Sun, M. Brandt, M.S. Dargusch, Thermally enhanced machining of hard-to-machine materials - A review, Int. J. Mach. Tools. Manuf. 50 (2010) 663-680

77. C.R. Dandekar, Y.C. Shin, J. Barnes, Machinability improvement of titanium alloy $(\mathrm{Ti}-6 \mathrm{Al}-4 \mathrm{~V})$ via $\mathrm{LAM}$ and hybrid machining, Int. J. Mach. Tools. Manuf. 50 (2010) 174-182

78. M.J. Bermingham, W.M. Sim, D. Kent, S. Gardiner, M.S. Dargusch, Tool life and wear mechanisms in laser assisted milling Ti-6Al-4V, Wear 322-323 (2015) $151-163$

79. M.J. Bermingham, P. Schaffarzyk, S. Palanisamy, M.S. Dargusch, Laser-assisted milling strategies with different cutting tool paths, Int. J. Adv. Manuf. Technol. 74 (2014) $1487-1494$

80. Y. Gao, G. Wang, M.J. Bermingham, M.S. Dargusch, Cutting force, chip formation, and tool wear during the laser-assisted machining a near-alpha titanium alloy BTi-6431S, Int. J. Adv. Manuf. Technol. 79 (2015) 1949-1960

81. S. Sun, M. Brandt, M.S. Dargusch, The Effect of a Laser Beam on Chip Formation during Machining of Ti6Al4V Alloy, Metall. Mater. Trans. A 41 (2010) 1573-1581

82. G. Germain, P. Dal Santo, J.L. Lebrun, Comprehension of chip formation in laser assisted machining, Int. J. Mach. Tools. Manuf. 51 (2011) 230-238

83. Y. Ayed, G. Germain, A.P. Melsio, P. Kowalewski, D. Locufier, Impact of supply conditions of liquid nitrogen on tool wear and surface integrity when machining the Ti-6Al4V titanium alloy, Int. J. Adv. Manuf. Technol. 93 (2017) 1199-1206

84. S.Y. Hong, Y. Ding, W. Jeong, Friction and cutting forces in cryogenic machining of Ti-6Al-4V, Int. J. Mach. Tools. Manuf. 41 (2001) 2271-2285

85. M. Dhananchezian, M. Pradeep Kumar, Cryogenic turning of the $\mathrm{Ti}-6 \mathrm{Al}-4 \mathrm{~V}$ alloy with modified cutting tool inserts, Cryogenics 51 (2011) 34-40

86. U. Kumar, P. Senthil, Performance of cryogenic treated multi-layer coated WC insert in terms of machinability on titanium alloys Ti-6Al-4V in dry turning, Mater. Today Proc. (2019) S2214785319333656

87. W.S. Yip, S. To, Sustainable manufacturing of ultraprecision machining of titanium alloys using a magnetic field and its sustainability assessment, Sustain. Mater. Technol. 16 (2018) 38-46

88. P.D. Hartung, B.M. Kramer, B.F. von Turkovich, Tool Wear in Titanium Machining, CIRP Ann. 31 (1982) $75-80$

89. K. Maity, S. Pradhan, Investigation of FEM Simulation of Machining of Titanium Alloy Using Microgroove Cutting Insert, Silicon. 10 (2018) 1949-1959 
90. R. Singh, J.S. Khamba, Mathematical modeling of tool wear rate in ultrasonic machining of titanium, Int. J. Adv. Manuf. Technol. 43 (2009) 573-580

91. M.H. Ali, M.N.M. Ansari, B.A. Khidhir, B. Mohamed, A.A. Oshkour, Simulation machining of titanium alloy (Ti-6Al-4V) based on the finite element modeling, J. Braz. Soc. Mech. Sci. Eng. 36 (2014) 315-324

92. R. Li, A.J. Shih, Finite element modeling of 3D turning of titanium, Int. J. Adv. Manuf. Technol. 29 (2006) 253-261

93. M.I. Sadik, E. Coronel, M. Lattemann, Influence of characteristic properties of PCD grades on the wear development in turning of $\beta$-titanium alloy (Ti5Al5V5Mo3Cr), Wear 426-427 (2019) 1594-1602

94. A. Shokrani, I. Al-Samarrai, S.T. Newman, Hybrid cryogenic MQL for improving tool life in machining of Ti6Al-4V titanium alloy, J. Manuf. Process 43 (2019) 229-243

95. L.M. Hlaváč, L. Gembalová, P. Štěpán, I.M. Hlaváčová, Improvement of abrasive water jet machining accuracy for titanium and TiNb alloy, Int. J. Adv. Manuf. Technol. 80 (2015) 1733-1740

96. S. Jeelani, K. Ramakrishnan, Surface damage in machining titanium 6Al-2Sn-4Zr-2Mo alloy, J. Mater. Sci. 20 (1985) $3245-3252$

97. R. Lapovok, A. Molotnikov, Y. Levin, A. Bandaranayake, Y. Estrin, Machining of coarse grained and ultra fine grained titanium, J. Mater. Sci. 47 (2012) 4589-4594

98. Z. Liu, J. Xu, S. Han, M. Chen, A coupling method of response surfaces (CRSM) for cutting parameters optimization in machining titanium alloy under minimum quantity lubrication (MQL) condition, Int. J. Precis. Eng. Manuf. 14 (2013) 693-702

99. K.-H. Park, G.-D. Yang, M.A. Suhaimi, D.Y. Lee, T.-G. Kim, D.-W. Kim, et al. The effect of cryogenic cooling and minimum quantity lubrication on end milling of titanium alloy Ti-6Al-4V, J. Mech. Sci. Technol. 29 (2015) $5121-5126$

100. Z. Ping, W. Youqiang, Research on High Speed Machining of TC17 Titanium Alloy Under Extreme Environments, Trans. Indian Inst. Met. 71 (2018) 831-839

101. J. Bannard, On the electrochemical machining of some titanium alloys in bromide electrolytes, J. Appl. Electrochem. 6 (1976) 477-483

102. S. Sun, J. Harris, Y. Durandet, M. Brandt, Effect of laser beam on machining of titanium alloys, Pac. Int. Conf. Appl. Lasers. Opt. 2008 (2008) 44-49

103. H. Jing, M. Zhou, J. Yang, S. Yao, Stable and Fast Electrical Discharge Machining Titanium Alloy with MIMO Adaptive Control System, Procedia. CIRP 68 (2018) 666-671

104. J.F. Kahles, M. Field, D. Eylon, F.H. Froes, Machining of Titanium Alloys. JOM 37 (1985) 27-35

105. W. Song, Z. Peng, P. Li, P. Shi, S.-B. Choi, Annular Surface Micromachining of Titanium Tubes Using a Magnetorheological Polishing Technique, Micromachines 11 (2020) 314

106. Y. Wang, D. Hu, Study on the inner surface finishing of tubing by magnetic abrasive finishing, Int. J. Mach. Tools. Manuf. 45 (2005) 43-49

107. A. Sharma, M.D. Sharma, R. Sehgal, Experimental Study of Machining Characteristics of Titanium Alloy (Ti-6Al-4V), Arab. J. Sci. Eng. 38 (2013) 3201-3209
108. D. Sharma, S. Mohanty, A.K. Das, Surface modification of titanium alloy using hBN powder mixed dielectric through micro-electric discharge machining, Surf. Coat. Technol. 381 (2020) 125157

109. N. Ahmed, S. Ahmad, S. Anwar, A. Hussain, M. Rafaqat, M. Zaindin, Machinability of titanium alloy through laser machining: material removal and surface roughness analysis, Int. J. Adv. Manuf. Technol. 105 (2019) 3303-3323

110. Y. He, W. Gan, F. Yin, J. Zhao, B. Xu, Q. Yu, et al. Multi-physical field coupling for vibration feed electrochemical machining of diamond-shaped hole in titanium alloy, Int. J. Adv. Manuf. Technol. 106 (2020) 1409-1420

111. F. Wang, J. Zhao, Y. Lv, Z. Yang, J. Yao, Y. He, et al. Electrochemical machining of deep narrow slits on TB6 titanium alloys, Int. J. Adv. Manuf. Technol. 92 (2017) 3063-3071

112. W. Liu, S. Ao, Y. Li, Z. Liu, Z. Wang, Z. Luo, et al. Jet electrochemical machining of TB6 titanium alloy, Int. J. Adv. Manuf. Technol. 90 (2017) 2397-2409

113. N.J. Churi, Z.J. Pei, C. Treadwell, Rotary ultrasonic machining of titanium alloy: Effects of machining variables, Mach. Sci. Technol. 10 (2006) 301-321

114. R. Singh, J.S. Khamba, Investigation for ultrasonic machining of titanium and its alloys, J. Mater. Process Technol. 183 (2007) 363-367

115. S.D. Dhobe, B. Doloi, B. Bhattacharyya, Surface characteristics of ECMed titanium work samples for biomedical applications, Int. J. Adv. Manuf. Technol. 55 (2011) $177-188$

116. N. Yu, X. Fang, L. Meng, Y. Zeng, D. Zhu, Electrochemical micromachining of titanium microstructures in an NaClethylene glycol electrolyte, J. Appl. Electrochem. 48 (2018) 263-273

117. Y. Liu, N. Qu, Obtaining high surface quality in electrolyte jet machining TB6 titanium alloy via enhanced product transport, J. Mater. Process Technol. 276 (2020) 116381

118. W. Liu, Z. Luo, Y. Li, Z. Liu, K. Li, J. Xu, et al. Investigation on parametric effects on groove profile generated on Ti1023 titanium alloy by jet electrochemical machining, Int. J. Adv. Manuf. Technol. 100 (2019) 2357-2370

119. S. Sarkar, S. Mitra, B. Bhattacharyya, Parametric optimisation of wire electrical discharge machining of $\gamma$ titanium aluminide alloy through an artificial neural network model, Int. J. Adv. Manuf. Technol. 27 (2006) 501-508

120. B.B. Pradhan, M. Masanta, B.R. Sarkar, B. Bhattacharyya, Investigation of electro-discharge micro-machining of titanium super alloy, Int. J. Adv. Manuf. Technol. 41 (2009) 1094-1106

121. A. Secilmis, A.M. Olmez, M. Dilmec, H.S. Halkaci, O. Inan, Determination of optimal EDM machining parameters for machined pure titanium-porcelain adhesion, Int. J. Adv. Manuf. Technol. 45 (2009) 55-61

122. A. Kumar, V. Kumar, J. Kumar, Multi-response optimization of process parameters based on response surface methodology for pure titanium using WEDM process, Int. J. Adv. Manuf. Technol. 68 (2013) 2645-2668

123. J. Kumar, Investigations into the surface quality and microhardness in the ultrasonic machining of titanium (ASTM GRADE-1), J. Braz. Soc. Mech. Sci. Eng. 36 (2014) $807-823$ 
124. A. Kumar, V. Kumar, J. Kumar, Semi-empirical model on MRR and overcut in WEDM process of pure titanium using multi-objective desirability approach, J. Braz. Soc. Mech. Sci. Eng. 37 (2015) 689-721

125. R. Chalisgaonkar, J. Kumar, Investigation of the machining parameters and integrity of the work and wire surfaces after finish cut WEDM of commercially pure titanium, J. Braz. Soc. Mech. Sci. Eng. 38 (2016) 883-911

126. B. Khosrozadeh, M. Shabgard, Effects of hybrid electrical discharge machining processes on surface integrity and residual stresses of Ti-6Al-4V titanium alloy, Int. J. Adv. Manuf. Technol. 93 (2017) 1999-2011

127. S. Kumar, R. Singh, A. Batish, T.P. Singh, R. Singh, Investigating surface properties of cryogenically treated titanium alloys in powder mixed electric discharge machining, J. Braz. Soc. Mech. Sci. Eng. 39 (2017) 2635-2648

128. R. Kumar, S. Roy, P. Gunjan, A. Sahoo, D.D. Sarkar, R.K. Das, Analysis of MRR and Surface Roughness in Machining Ti-6Al-4V ELI Titanium Alloy Using EDM Process, Procedia. Manuf. 20 (2018) 358-364

129. M.Y. Tsai, C.S. Fang, M.H. Yen, Vibration-assisted electrical discharge machining of grooves in a titanium alloy (Ti-6A-4V), Int. J. Adv. Manuf. Technol. 97 (2018) 297-304

130. A. Kushwaha, T. Jadam, S. Datta, M. Masanta, Assessment Of Surface Integrity During Electrical Discharge Machining Of Titanium Grade 5 Alloys (Ti-6Al-4V), Mater. Today Proc. 18 (2019) 2477-2485

131. A.V.S. Ram Prasad, K. Ramji, M. Kolli, An Experimental Investigation on Machining Parameters of Titanium Alloy Using WEDM, Mater. Today Proc. 18 (2019) A12-A16

132. A.K. Sahu, S.S. Mahapatra, Performance analysis of tool electrode prepared through laser sintering process during electrical discharge machining of titanium, Int. J. Adv. Manuf. Technol. 106 (2020) 1017-1041

133. A. Shard, D. Shikha, V. Gupta, M.P. Garg, Effect of $\mathrm{B} 4 \mathrm{C}$ abrasive mixed into dielectric fluid on electrical discharge machining, J. Braz. Soc. Mech. Sci. Eng. 40 (2018) 554

134. M. Kolli, A. Kumar, Assessing the Influence of Surfactant and B4C Powder Mixed in Dielectric Fluid on EDM of Titanium Alloy, Silicon 11 (2019) 1731-1743

135. X. Wang, Z. Liu, R. Xue, Z. Tian, Y. Huang, Research on the influence of dielectric characteristics on the EDM of titanium alloy, Int. J. Adv. Manuf. Technol. 72 (2014) 979-987

136. M. Kolli, A. Kumar, Effect of dielectric fluid with surfactant and graphite powder on Electrical Discharge Machining of titanium alloy using Taguchi method, Eng. Sci. Technol. Int. J. 18 (2015) 524-535

137. B. Jabbaripour, M.H. Sadeghi, M.R. Shabgard, H. Faraji, Investigating surface roughness, material removal rate and corrosion resistance in PMEDM of $\gamma$-TiAl intermetallic, J. Manuf. Process 15 (2013) 56-68

138. H.-M. Chow, L.-D. Yang, C.-T. Lin, Y.-F. Chen, The use of $\mathrm{SiC}$ powder in water as dielectric for micro-slit EDM machining, J. Mater. Process Technol. 195 (2008) $160-170$

139. B.H. Yan, H. Tsai Chung, F. Yuan Huang, The effect in EDM of a dielectric of a urea solution in water on modifying the surface of titanium, Int. J. Mach. Tools. Manuf. 45 (2005) 194-200

140. S.L. Chen, B.H. Yan, F.Y. Huang, Influence of kerosene and distilled water as dielectrics on the electric discharge machining characteristics of Ti-6A1-4V, J. Mater. Process Technol. 87 (1999) 107-111

141. H.-M. Chow, B.-H. Yan, F.-Y. Huang, J.-C. Hung, Study of added powder in kerosene for the micro-slit machining of titanium alloy using electro-discharge machining, J. Mater. Process Technol. 101 (2000) 95-103

142. R.D. Dyaminov, A.N. Mal'tsev, G.V. Kargin, Electrochemical machining of titanium-rotor cast blades for vortex pumps, Chem. Pet. Eng. 13 (1977) 817-818

143. A.D. Davydov, T.B. Kabanova, V.M. Volgin, Electrochemical machining of titanium. Review, Russ. J. Electrochem. 53 (2017) 941-965

144. S. Hizume, W. Natsu, Influence of Machining Conditions on ECM Characteristics of Titanium Alloy in Shape Generation by Scanning Tool Electrode, Procedia. CIRP 68 (2018) 746-750

145. S.S. Anasane, B. Bhattacharyya, Experimental investigation into fabrication of microfeatures on titanium by electrochemical micromachining, Adv. Manuf. 4 (2016) $167-177$

146. A.K. Dubey, V. Yadava, Laser beam machining-A review, Int. J. Mach. Tools. Manuf. 48 (2008) 609-628

147. R. Farasati, P. Ebrahimzadeh, J. Fathi, R. Teimouri, Optimization of laser micromachining of Ti-6Al-4V, Int. J. Lightweight Mater. Manuf. 2 (2019) 305-317

148. V. Tangwarodomnukun, P. Likhitangsuwat, O. Tevinpibanphan, C. Dumkum, Laser ablation of titanium alloy under a thin and flowing water layer, Int. J. Mach. Tools. Manuf. 89 (2015) 14-28

149. S. Duangwas, V. Tangwarodomnukun, C. Dumkum, Development of an Overflow-Assisted Underwater Laser Ablation, Mater. Manuf. Process 29 (2014) 1226-1231

150. V. Tangwarodomnukun, Overflow-assisted laser machining of titanium alloy: surface characteristics and temperature field modeling, Int. J. Adv. Manuf. Technol. 88 (2017) $147-158$

151. L. Balamuth, Method and means for removing material from a solid body, US2580716A, 1952

152. L. Heng, Y.J. Kim, S.D. Mun, Review of Superfinishing by the Magnetic Abrasive Finishing Process, High Speed Mach. 3 (2017). https://doi.org/10.1515/hsm-2017-0004

153. X. Sun, Y. Zou, Study on Electrolytic Magnetic Abrasive Finishing for Finishing Stainless Steel SUS304 Plane with a Special Compound Machining Tool, J. Manuf. Mater. Process 2 (2018) 41

154. P. Kala, P.M. Pandey, Comparison of finishing characteristics of two paramagnetic materials using double disc magnetic abrasive finishing, J. Manuf. Process 17 (2015) 63-77

155. A. Barman, M. Das, Design and fabrication of a novel polishing tool for finishing freeform surfaces in magnetic field assisted finishing (MFAF) process, Precis. Eng. 49 (2017) 61-68

156. A. Barman, M. Das, Toolpath generation and finishing of bio-titanium alloy using novel polishing tool in MFAF process, Int. J. Adv. Manuf. Technol. 100 (2019) 1123-1135 
157. A. Barman, M. Das, Magnetic field assisted finishing process for super-finished $\mathrm{Ti}$ alloy implant and its 3D surface characterization, J. Micromanufacturing 1 (2018) 154-169

158. Z. Fan, Y. Tian, Q. Zhou, C. Shi, Enhanced magnetic abrasive finishing of Ti-6Al-4V using shear thickening fluids additives, Precis. Eng. 64 (2020) 300-306

159. W. Li, Y. Chen, M. Cheng, Y. Lv, Effect of Magnetic Head Shape on Processing of Titanium Alloy Wire by Magnetic Abrasive Finishing, Materials 13 (2020) 1401
160. K. Zhou, Y. Chen, Z.W. Du, F.L. Niu, Surface integrity of titanium part by ultrasonic magnetic abrasive finishing, Int. J. Adv. Manuf. Technol. 80 (2015) 997-1005

161. M. Kolli, A. Kumar, Effect of Boron Carbide Powder Mixed into Dielectric Fluid on Electrical Discharge Machining of Titanium Alloy, Procedia. Mater. Sci. 5 (2014) 1957-1965

162. B. Kumar, Baroi, S. Kar, P. Kumar, Patowari, Electric Discharge Machining of Titanium Grade 2 Alloy and its Parametric Study, Mater. Today Proc. 5 (2018) 5004-5011

Cite this article as: Samuel Ranti Oke, Gabriel Seun Ogunwande, Moshood Onifade, Emmanuel Aikulola, Esther Dolapo Adewale, Olumide Emmanuel Olawale, Babapelumi Ebun Ayodele, Fredrick Mwema, Japheth Obiko, and Michael Oluwatosin Bodunrin, An overview of conventional and non-conventional techniques for machining of titanium alloys, Manufacturing Rev. 7, $34(2020)$ 